\title{
REGISTER ZUM REPERTORIUM
}

\section{Namen}

Alle Autoren (auch Verfasser von Übersetzungen und Bearbeitungen) sind nach dem Vornamen geordnet. Für die alphabetische Sortierung werden die Präpositionen vor den Namenszusätzen nicht berücksichtigt. Wenn dem Autor ein Repertoriumseintrag gewidmet ist, wird auf den Eintrag verwiesen. Falls er aber lediglich in einer Rubrik erwähnt wird, wird diese nach der Repertoriumsnummer in Klammern angegeben: Übers $<$ etzungen $>$, Bearb $<$ eitungen $>$, Fass $<$ ungen $>$.

Adam Werner von Themar R56b (Übers./Bearb.)

Ademarius R51

Ademarus Parisiensis R51

Adomarus R51

Adrianus Carthusiensis R56b (Übers./Bearb.)

Aelred of Rievaulx A15

Aelredus Rievallensis abbas A15

Al-Kindi A3

Albertano da Brescia R24

Albertanus Brixiensis R24

Albertino Mussato R47

Alberto Mussato R47

Albertinus Mussatus R47

Albrecht von Eyb R56b (Übers./Bearb.)

Aldemarus R51

Amandus de Swebia (Amandus Teutonicus) R54

Andomarus R51

Andrea da Grossetto R24 (Übers./Bearb.)

Antoninus Florentinus R46 (Übers./Bearb.)

Arnald von Villanova R36, R58

Arnaldus de Villanova R36, R58

Arnau de Vilanova R36, R58

Arnoldus Luca (Arnoldus Saxo) R28

Audomarus R51

Bart(h)olus de Saxoferrato R5, R5c

Bartolo da Sassoferrato R5, R5c

Bonaventura de Albano (Bonaventura a Bagnorea/da Bagnoregio/de Balneoregio) R27

Bonromeus Basacomatrius (de Basacomatribus) Bononiensis A23

Borromeo di Bologna A22

Caesarius Heisterbacensis prior (Cesarius von Heisterbach) R16

Caterina Benincasa Al

Catharina Senensis Al

Chaucer R24 (Übers./Bearb.), R39 (Übers./Bearb.)

Colard Mansion R48 (Übers./Bearb.)

Çuan dea Lusa R24 (Übers./Bearb.) 
Dietrich von Königsaal R55

Dirc Potter R24 (Übers./Bearb.)

Dondinus Papiensis R45

Eberhardus de Tremaugon R64, R37 (Übers./Bearb.)

Elias Rubeus Tripolanensis (Elias de Thriplow) R18

Engelbertus Admontensis abbas R34

Engelbert von Admont R64

Engelbert Poetsch R64

Étienne de Gallardon R10

Évrart de Trémaugon R64, R37 (Übers./Bearb.)

Francesco Petrarca R56

Francisco de Madrid R56b (Übers./Bearb.)

Franciscus Petrarcha R56

Frater Heila R58 (Autor)

Frater Nicolaus de Spina R77

Gallus Aulaeregiae (Gallus von Königsaal/de Zbraslav) R55

Georg Alt R5c (Übers./Bearb.)

Georg Spalatin R56b (Übers./Bearb.)

Georgius laicus R13

Geri d'Arezzo R42

Gerius Frederici de Aretio R42

Giacomo Palladini A17

Gilbertus de Tornaco R25

Giovanni Conversini da Ravenna (Giovanni Conversano/di Conversino) R71

Giovanni Fidanza R27

Giovanni da Ravenna R71

Giovanni de San Miniato R56b (Übers./Bearb.)

Giovanni Villani R46 (Übers./Bearb.)

Gonzalo Sánchez de Uceda R32a (Übers./Bearb.)

Gui de Colle di Mezzo (Gui de Colmieu) R5a

Guibert van Doornik (Guibert de Tournai) R25

Guibertus Tornacensis R25

Guido de Collemedio ep. Cameracensis R5a

Guido de Cumis (Guido de Guinis) R22

Guillelmus Baufeti R38

Guillelmus de Moerbeke A14

Guillelmus de Ockham R52, R53

Guillelmus de Parisiis R38

Guillelmus Remingtonus (Guillelmus Rymston) R72

Hans Folz R26 (Übers./Bearb.)

Havel R55

Henricus de Hassia senior (Henricus Heinbuche de Hassia) R70

Heinrich (Heinbuche) von Langenstein R70

Henricus Montensis R54

Henricus Suso R54

Heinrich Seuse R54

Hermann Korner R46 (Übers./Bearb.)

Hugues de Digne R30

Hugo de Sancto Victore A18 
Iacobellus de Misa R66a (Übers.)

Iacobus ab Ancharano Al7

Iacobus de Misa R66a (Übers.)

Iacobus Palladinus A17

Iacobus de $\mathrm{T}(\mathrm{h})$ eramo $\mathrm{A} 17$

Inghetto Contardo R33

Ingetus Contardus R33

Innocentius III Papa R8

Iohannes Balbus (Iohannes de Balbis) R31

Iohannes Betsam R29

Iohannes Conversinus de Ravenna R71

Iohannes Dambacensis (Iohannes de Dambach/de Dambico/de Dambuco) R61

Iohannes de Einczinsteyn R67

Iohannes Fabri abbas Sancti Vedasti ep. Carnotensis R68

Iohannes de Frankenstein Aulaeregiae abbas R55

Iohannes de Genzenstein R67

Iohannes Gobi(i) Alestensis iun. R46

Iohannes Hildesheimensis R62

Iohannes de Ianua (Iohannes Ianuensis de Balbis) R31

Iohannes de Ienstein (Iohannes de Ienzenstein) R67

Iohannes de Lignano R68 (Datierung), R69 (Inhalt)

Iohannes Lotharius e comitibus Signiae R8

Iohannes de Montesono Valentinus R78

Iohannes Muretus R73

Iohannes Paccianus (Iohannes Peachamus/Peccanus/Pech/de Pecham/Pechanus/ Pecranus/Peczanus/Pesch/Pescham/Petsan/Piccianus/de Pitcham/Pizanus) R29

Iohannes Ravennatensis R71

Iohannes de Tambach (Iohannes de T(h)ambaco/de T(h)ambico/de $\mathrm{T}(\mathrm{h}) \mathrm{ambuco}$ ) R 61

Iohannes de Thesen (Iohannes de Tetzin) R58

Iohannes Wyclif R66j

Iohannes de Zambaco (Iohannes de Zambico/de Zambuco) R61

Jacob Ayrer R5b (Übers./Bearb.)

Jacob van Maerlant R5b (Übers./Bearb.)

Jakob von Jüterbog R3

Jakob von Paradies R3

Jakoubek von Střibro R66a (Übers.)

Jan van Boendale R24 (Übers./Bearb.)

Jan z Jenštejna R67

Jean Baudoin de Rosières-aux-Salines R46 (Übers./Bearb.)

Jean Daudin R56b (Übers./Bearb.)

Jean Gobi R46

Jean de Justice R5a (Übers./Bearb.)

Jean Lefèvre R68

Jean Muret R73

Joan Montson R78

Johann Hartlieb R16 (Übers./Bearb.)

Johann von Frankenstein R55

Johann von Jenstein R67

Johannes von Dambach R61

Johannes von Hildesheim R62

John Sharpe R57a (Übers./Bearb.)

John Trevisa R37 (Übers./Bearb.) 
John Wiclef (John Wiclif/Wyclif/Wyclyf/Wycliffe) R66 Joseph Pollinger R37 (Übers./Bearb.)

Juan de Monzón R78

Katharina von Siena Al

Lombardo della Seta R60

Lombardus Patavinus (a Serico) R60

Lotharius de comitibus Signiae (Lotharius Signinus) R8

Lotario de Conti R8

Maestre Pedro R24 (Übers./Bearb.)

Magninus de Magnis (Magninus Mediolanensis) R48

Magnus Mediolanensis R48

Maino de Mainerii R48

Manfredus rex Siciliae (Manfred von Sizilien) A3

Marcus de Lindaugia R63, A6

Margareta Porete (Marguerite Porete) A4

Marquard Funke R63, A6

Marquard von Lindau R63, A6

Marquardus de Lindaugia R63, A6

Mateusz z Krakowa R75

Matthaeus Cracoviensis ep. R75

Matthäus von Krakau R75

Maynus de Mayneriis R48

Michael de Praga R74

Moneta Cremonensis R14, R15

Nicholas Donin A10

Nicholas Radcliffe R65

Nicolás Eymerich R76

Nicolau Eimeric R76

Nicolaus de Argentina R26

Nicolaus Aymerich R76

Nicolaus Comes (Nicolaus de Comitibus) R58

Nicolaus Eymerich (Nicolaus Eymerici) R76

Nicolaus Pergaminus R48

Nicolaus Radclyf R65

Nicolaus de Spina R77

Niklas von Wyle R56b (Übers./Bearb.)

Nikolaus von Straßburg R26

Odomarus parisiensis R51

Og(l)erius de Locedio abbas (Og(l)erius de Lucedio/Trino/Tridino) A7

Otto der Rasp R19 (Übers./Bearb.)

Pedro de Alcántara R27 (Übers./Bearb.)

Pedro de Luna R61 (Übers./Bearb.)

Perfectus de Malatestis abbas Sitriensis ep. Pattensis R69

Perfetto Malatesta R69

Peter of Cornwall R12

Peter Stahel R56b (Übers./Bearb.)

Peter von Zittau R55

Petrus OP A20 
Petrus de Alliaco R52 (Übers./Bearb.)

Petrus canonicus Sanctae Trinitatis Londini R12

Petrus Compostellanus R43

Petrus de Cornubia (Cornubiensis) Sanctae Trinitatis Londiniensis prior R12

Petrus de Penne (Petrus de Pennis) R59

Petrus de Vinea (Petrus de Vineis) A22

Petrus Zittaviensis Aulaeregiae abbas R55

Pierre d'Ailly R52 (Übers./Bearb.)

Pietro della Vigna A22

Proklos A14

Ps. Albertus Magnus R35

Ps. Anselm von Canterbury R21

Ps. Anselmus Cantuariensis archiep. R21

Ps. Aristoteles A3

Ps. Arnaldus de Villanova R39, R58

Ps. Augustinus R6

Ps. Bart(h)olus de Saxoferrato R5

Ps. Hugo de Digna R30

Ps. Iacobus de Paradiso R3

Ps. Robertus Grosseteste A18

Raimundus siehe Raymundus

Ramon Astruc de Cortielles R79

Ramon Llull R32

Raymundus Astruch de Cortyelles R79

Raymundus Lullus R32

Remigio Nannini (Remigio Fiorentino) R56b (Übers./Bearb.)

Renaut de Louhans R24 (Übers./Bearb.)

Richalm von Schöntal R17

Richalmus Speciosae Vallis abbas (Richalmus de Schöntal) R17

Richard Fitzralph R57

Richard Le Ruys A11

Richard von Nassyngton R46 (Übers./Bearb.)

Richard Rufus of Cornwall Al1

Richardus de Anglia R44

Richardus Coningtonus (Richardus de Conyngton, Covedunus) R44

Richardus Cornubiensis A11

Richardus filius Radulphi Armachanus archiep. R57

Richardus Radulphi R57

Richardus Rufus Cornubiensis A11

Robert the Englishman R50

Robertus Anglicus R50

Rodericus Toletanus archiep. A8

Rodericus Ximenii de Rada (Rodrigo Jiménez de Rada) A8

Sebastiano de Rossi l'Inferigno R24 (Übers./Bearb.)

Servasanctus de Faventia A21

Servasanto da Faenza A21

Soffredo del Grazia R24 (Übers./Bearb.)

Stephan Vigilius R56b (Übers./Bearb.)

Stephanus de Galardone (Stephanus de Galardun/de Gualardon/de Guallardone) R10

Stephanardus de Vicomercato R35

Stefanardo de Vimercate R35 
Theobaldus de Saxania R26 (Autor), R49 (Fassungen)

Theodoricus Aulaeregiae prior R55

Thibaut de Sézanne R26 (Autor), R49 (Fassungen)

Thomas Twyne R56b (Übers./Bearb.)

Ulrich Tenngler R5c (Übers./Bearb.)

Vincentius Kadlubek Cracoviensis ep. (Vincentius Kadlubkonis) R9

Walter Bower R46 (Übers./Bearb.)

Wilhelm von Moerbeke Al4

William of Occam (William of Ockham) R52, R53

William of Remington (William Rimington/Rymington/Rymyngton) R72

Wincenty Kadłubek R9 
Alle Titelvarianten der behandelten Werke sowie Titel von Fassungen, Übersetzungen und Bearbeitungen finden sich hier alphabetisch geordnet. Es wird auf den jeweiligen Repertoriumseintrag verwiesen, gegebenenfalls unter Angabe der Rubrik: Übers $<$ etzungen $>$, Bearb $<$ eitungen $>$, Fass $<$ ungen $>$.

Abbreviatio dyalogi Okan R52 (Übers./Bearb.)

Ad amicum volentem nubere $\mathrm{R} 74 \mathrm{~b}$

Ad Franciscum Petrarcam Lombardus a Serico de dispositione vitae suae dialogus R60

Advocacia beatae Mariae virginis contra diabolum (daemonem) pro genere humano R5a

Ain kurtz gedichter process verteutschet R5c (Übers./Bearb.)

Ain schöner Dialogus zwischen ainem Priester und Ritter R37 (Übers./Bearb.)

Alphabetum catholicorum (ad inclitum Dominum regem Aragonum pro filiis erudiendis in elementis catholicae fidei) R36

Altercatio Cayn cum Christo R3

Altercatio diaboli contra Christum R2

Altercatio Divinitatis et Humanitatis A19

Argumenta quae fecit diabolus Christo pendenti in cruce ad probandum quod non debebat redimere genus humanum $\mathrm{R} 7 \mathrm{a}$

Aucto de acusación contra el género humano R5c (Übers./Bearb.)

Augustinus in dyalogo inter sanctam animam et Mariam de passione Domini R6

Auszug der Kinder Israel A6a

Bernhardstraktat A7

Boek van Merline R5b (Übers./Bearb.)

Buch der inbildung des ewigen lebens R27 (Übers./Bearb.)

Büchlein der ewigen Weisheit R54 (Fass.)

Casus Institutionum R22

Casus longi super Institutis R22

Chronica de gestis illustrium principum ac regum Poloniae R9

Chronica novella R46 (Übers./Bearb.)

Codex veritatis A2

Collocutio didascalica super elementis catholicae fidei R36

Colloquium cum beata virgine de passione Christi R21

Conflictus inter Deum et diabolum R2

Consolatio philosophiae R61

Consolatio theologiae R61

Consolatio Venetorum (et totius gentis desolatae) R32j

Consolatio vitae humanae R61

Consolatorium theologicum R61

Contemplatio animae et planctus Sanctae Mariae R6

Contemptus sublimitatis (et liber de animalibus) R48

Contentio de nobilitate generis et probitate animi R20

Contra casus fortuitos dialogus R47c

Contra trialogum Hockam R45

De adventu Messiae R32c

De amore R42 
De anima A13

De celebratione missae R75a

De cognitione habita apud daemones R7b, R8

De conceptione beatae Mariae virginis R79

De consolatione de obitu filii R71d

De consolatione rationis $\mathrm{R} 43$

De contemptu mortis R73

De contemptu mundi A18

De dispositione vitae suae R60

De dogmatibus Iohannis papae R52 (Datierung)

De dominio summi pontificis et ecclesiae militantis R65a

De erroribus Armenorum (quaestiones) R57a

De familiaritate Dei cum anima A16

De fide catholica contra Sarracenos R321

De fletu ecclesiae R68 (Datierung), R69 (Inhalt)

De iudiciis viciorum et virtutum R28

De lapide philosophorum R39

De laudibus dominae nostrae Sanctae Mariae R32f

De lite inter Naturam et Fortunam R47b

De lite Naturae et Fortunae R47b

De locutione angelorum $\mathrm{R} 32 \mathrm{u}$

De Maria et anima R6

De monarchia mundi ecclesiastica et temporali A17

De morte Aristotilis A3

De morte loquente cuidam magistro R40

De morte omnium hominum R40

De morte prologus $\mathrm{R} 40$

De morte sermo R40

De Nabuchodonosor A6b

De passione Domini R6

De pauperie Christi R57b

De pauperie Salvatoris R57b

De paupertate Salvatoris R57b

De planctu bonorum R68

De praedestinatione R15

De quatuor virtutibus cardinalibus pro eruditione principum R74a

De remediis R56b (Übers./Bearb.)

De remediis fortuitorum R28(Datierung; Inhalt); R56b (Übers./Bearb.)

De remediis in utramque fortunam $\mathrm{R} 56 \mathrm{~b}$

De remediis utriusque fortunae $\mathrm{R} 56 \mathrm{~b}$

De sacramento eucharistiae R14

De scismate R78

De secretis materiae R39

De secretis naturae R39

De secreto conflictu curarum mearum 56a

De septem sacramentis R38

De spiritu Guidonis R46

De viatico salutari animae inmortalis $\mathrm{R} 65 \mathrm{~b}$

Declaratio Raimundi (per modum dialogi edita contra aliquorum philosophorum et eorum sequacium opiniones erroneas et damnatas a venerabili patre domino episcopo Parisiensi) R32h

Defensorium ordinis Fratrum gloriosissimae Dei Genitricis Mariae de monte Carmelo R62

Dekalogerklärung A6a 
Der köcher wider die Juden R26 (Übers./Bearb.)

Descriptio mortis per quatuor philosophos R63

Descriptio mortis per tres philosophos R63

Destructorium vitiorum R48

Devota revelazione $\mathrm{Alb}$

Dialog mistrza Polikarpa ze Śmiercią R40 (Übers./Bearb.)

Dialoges of creatures moralysed R48 (Übers./Bearb.)

Dialogi varii R65a

Dialogo della Divina Providenza Ala

Dialogus R52

Dialogus brevis Alb

Dialogus ad cardinalem Reatinum super schismate ecclesiae orto tempore Urbani VI papae R78

Dialogus ad Guillelmum fratrem suum R51

Dialogus animae et corporis R27

Dialogus clerici et laici contra persecutores ecclesiarum R11

Dialogus concupiscentiae et rationis (de iis quae veram homini felicitatem conferant et beatitudinem) R34

Dialogus contra Lullistas R76

Dialogus contra Manichaeos qui Paterini vocantur R13

Dialogus creaturarum moralizatus R48

Dialogus curiosus de formalitatibus inter unum Dunsistam et unum Ochamistam R50

Dialogus de accedendo ad sacramentum altaris R75a

Dialogus de administratione sacramentorum R38

Dialogus de apprehensione seu de potentiis apprehensivis R35

Dialogus de custodia thesauri castitatis R74b

Dialogus de custodia virginitatis $\mathrm{R} 74 \mathrm{~b}$

Dialogus de potentia summi pontificis $\mathrm{R} 45$

Dialogus de potestate papae ad Iohannem XXII R45

Dialogus de praedestinatione inter Catholicum et Manichaeum R15

Dialogus de quaestionibus animae ad spiritum R31

Dialogus de quatuor exercitiis R27

Dialogus de sacramentis R38

Dialogus de statu ecclesiae militantis R29

Dialogus de statu saeculi R29

Dialogus de vera sapientia R56b (Übers./Bearb.)

Dialogus de virginitate (et castitate) R74b

Dialogus de vitis sanctorum fratrum Minorum R23

Dialogus illius excellentissimi regis Philippi et illius boni cantoris Parisiensis magistri Petri R10

Dialogus Innocentii inter Deum et peccatorem R8

Dialogus inter Ademarum et Guillelmum fratrem suum R51

Dialogus inter Aelredum et discipulum A15

Dialogus inter beatam virginem et animam fidelem R6

Dialogus inter catholicam veritatem et haereticam pravitatem $\quad$ R72

Dialogus inter Christum et Caym R3

Dialogus inter concupiscentiam et rationem R34

Dialogus inter Deum et peccatorem R8

Dialogus inter directorem et detractorem R62

Dialogus inter fratrem et vicarium R53

Dialogus inter Iohannem et Litteram R7la

Dialogus inter magistrum Policarpum et mortem R40

Dialogus inter Mariam et animam R6 
Dialogus inter mortem et magistrum Polycarpum R40 (Übers./Bearb.)

Dialogus libri vitae A8

Dialogus lucis et tenebrarum R19

Dialogus magnus visionum atque miraculorum $\mathrm{R} 16$

Dialogus Mariae et Anselmi R21

Dialogus miraculorum R16

Dialogus moralis R34

Dialogus Philippi regis et Petri cantoris R10

Dialogus rationis et conscientiae (de communione) R75a

Disputació de cinc savis R32g (Fass.)

Disputatio adversus Iudaeos Rl

Disputatio Catholici contra haereticos R13

Disputatio contra Iudaeos R59

Disputatio eremitae et Raymundi (super aliquibus dubiis quaestionibus Sententiarum magistri Petri Lombardi) R32i

Disputatio facta inter Ingetum Contardum mercatorem Ianuensem et quosdam sapientissimos Iudaeos R33

Disputatio fidei et intellectus $\mathrm{R} 32 \mathrm{k}$

Disputatio fidelis et infidelis $\mathrm{R} 32 \mathrm{e}$

Disputatio inter catholicum et haereticum R4

Disputatio inter Catholicum et Paterinum haereticum R13

Disputatio inter clericum et militem R37

Disputatio inter inimicum domesticum paupertatis et zelatorem paupertatis R30

Disputatio inter quendam priorem OP et spiritum Guidonis R46

Disputatio inter Raimundum et Averroistam R32r

Disputatio inter vicarium et fratrem minorem de confessionibus audiendis, solutione canonicae portionis ac perfectione status eiusdem ordinis ac mendicitate R53

Disputatio inter zelatorem paupertatis et inimicum domesticum eius R30

Disputatio Petri clerici et Raimundi phantastici R32t

Disputatio quinque hominum sapientium $\mathrm{R} 32 \mathrm{~g}$

Disputatio Raimundi et Averroistae de quinque quaestionibus R32m

Disputatio saecularis et Iacobitae R79

Disputatio sanctae Trinitatis super redemptione humani generis R77

Disputatio Synagogae et Ecclesiae R25

Dit van Maskeroen R5b (Übers./Bearb.)

Dolosa prodictio Lugi et Conselicis domini marchionis R71b

Dolosi astus narratio R71b

Dragmalogia de eligibile vitae genere R7le

Dyalogi de quinque universalibus A23

Dyalogus A21

Dyalogus Augustini inter sanctam animam et beatam virginem Mariam R6

Dyalogus de custodia virginitatis vel castitatis R74b

Dyalogus de elementis catholicae fidei R36

Dyalogus inter beatam virginem et animam fidelem R6

Dyalogus inter Synagogam et Ecclesiam de variis erroribus Talmuth iudaeorum R26

Dyalogus pro ecclesia contra synagogam R26

Dyalogus sanctorum fratrum Minorum R23

Dyalogus scismatis R78

Dyalogus sive speculum ecclesiae militantis R66a

Dyalogus zelatoris sanctissime paupertatis eiusque domestici inimici disputantium super ipsa paupertate R30

Dye Ansprach des Tewffels gegen unsern Herren R19 (Übers./Bearb.) 
Ein nützlicher gerichteshandel vor got dem almechtigen R5c (Übers./Bearb.)

El Secreto di Messer Francesco Petrarca R56a (Übers./Bearb.)

Epistola pacis R70

Epistola ruricolae R60

Errores Iudaeorum in Talmut R26 (Autor), R49 (Fassungen)

Eucharistie-Traktat A6c

Evidentia tragoediarum Senecae R47a

Exemplum de magistro Porphirio quomodo allocutus sit morti R40

Expositio libri Gerberi R51

Expositio Procli in Parmenidem Platonis A14

Expositio super summa Gerberi R51

Fioretti de'Rimedi contro fortuna R56b (Übers./Bearb.)

Flors de Patrarcha de Remeys de Cascuna Fortuna R56b (Übers./Bearb.)

Francisco Petrarcae de bono solitudinis epistola R60

Gudelig visdoms bog R54 (Übers./Bearb.)

Gudeliga snilles väckare R54 (Übers./Bearb.)

Het boec vander vier inwendige oefnigen R27 (Übers./Bearb.)

Historia de spiritu Guidonis R46

Historia Lugi et Conselicis R71b

Historia moralis Elysiae R71c

Historie van den Grale R5b (Übers./Bearb.)

Historischer Processus iuris R5b (Übers./Bearb.)

Horloge de Sapience R54 (Übers./Bearb.)

Horologium aeternae sapientiae R54

Horologium aureum divinae sapientiae R54

Horologium divinae sapientiae R54

Horologium sapientiae R54

Imago vitae R27

Innocentii tertii dialogus inter Deum et peccatorem R8

Interrogatio sancti Anselmi R21

Interrogativa sancti Anselmi R21

L'Advocacie Notre-Dame ou la Vierge Marie plaidant contre le diable R5a (Übers./ Bearb.)

Lamentatio sancti Anselmi de Passione Domini R21

Layen Spiegel R5c (Übers./Bearb.)

Le dialogue des créatures R48 (Übers./Bearb.)

Le mirouer des simples ames A4

Le phantastique R32t (Übers.)

Le songe du vergier R64 (Übers./Bearb.)

Legatio prophetarum ad Deum pro incarnatione Filii Dei $\quad$ R77

Lere und Unterweisung R24 (Übers./Bearb.)

Libellus bilogorum R67b

Libellus contra Iudaeos (nomine Thulmoth) R59

Libellus de natali pueri (parvuli) R32n

Libellus de quatuor exercitiis R27

Libellus de scola et morte R40

Libellus diaboli contra genus humanum R5a

Libellus procuratoris in quo diabolus producit litem coram iudice omnipotente Deo contra genus humanum R5b 
Liber consolationis et consilii R24

Liber contra Iudaeos R49, R59

Liber contra Iudaeos nomine Thalamoth R59

Liber contradictionis R32p

Liber de abusu quatuor passionum R56b (Übers./Bearb.)

Liber de civitate mundi $\mathrm{R} 32 \mathrm{x}$

Liber de consilio dignitatum divinarum $\mathrm{R} 32 \mathrm{x}$

Liber de consolatione A22

Liber de consolatione eremitae R32v, R32v

Liber de contemptu sublimitatis R48

Liber de custodia virginitatis (et castitatis) R74b

Liber de Deo maiore et Deo minore R32w

Liber de disputatione fidelis et infidelis $\mathrm{R} 32 \mathrm{e}$

Liber de efficiente et effectu R32r

Liber de gentili et tribus sapientibus R32a

Liber de laudibus beatissimae virginis Mariae qui et ars intentionum appellari potesti R32f

Liber de natali parvuli pueri Jesu R32n

Liber de natali pueri (parvuli) R32n

Liber de pomo A3

Liber de quaestione valde alta et profunda R32s

Liber de quaestionibus Armenorum R57a

Liber de quinque sapientibus $\mathrm{R} 32 \mathrm{~g}$

Liber de sacramentis R38

Liber de Sancta Maria R32f

Liber de septem sacramentis R38

Liber de Spiritu Sancto R32b

Liber de statu saeculi R29

Liber de syllogismis contradictionis $\mathrm{R} 32 \mathrm{q}$

Liber de syllogismis contradictoriis $\mathrm{R} 32 \mathrm{q}$

Liber dialogorum R67a

Liber disputationis Petri et Raimundi R32t

Liber disputationis Raimundi christiani et Homeri Sarracenii R32l

Liber disputationum Petri contra Symonem Iudaeum de confutatione Iudaeorum R12

Liber lamentationis Philosophiae R32o

Liber natalis parvuli pueri Jesu R32n

Liber natalis pueri parvuli Christi (Iesu) R32n

Liber Naturae et Fortunae R47b

Liber notabilium Arnoldi Luce de consolatione Senece R28 (Dat./Bearb.)

Liber qui dicitur Pergaminus R48

Liber qui est de civitate mundi R32x

Liber (qui est) de consolatione eremitarum R32v

Liber qui est de Deo maiore et minore R32w

Liber qui est de disputatione fidei et intellectus $\mathrm{R} 32 \mathrm{k}$

Liber qui est de efficiente et effectu R32r

Liber qui est de locutione angelorum R32u

Liber qui est de quaestione valde alta et profunda R32s

Liber qui est de syllogismis contradictoriis R32q

Liber revelationum Richalmi abbatis R17

Liber seu dialogus de quaestione seu lite inter Fortunam et Naturam R47b

Liber super Psalmum Quicumque vult R32d

Liber Talmoth seu altercationes contra Iudaeos R49

Liber Tartari et Christiani R32d 
Liber visionum Richalmi R17

Libri dialogorum R16

Libri visionum R16

Libro de las consolaciones de la vida humana R61 (Übers./Bearb.)

Libro de los consejos e de los consejeros R24 (Übers./Bearb.)

Libro de Santa Maria R32f (Übers./Bearb.)

Libro del gentil e de los tres sabios R32a (Übers./Bearb.)

Libro della divina dottrina Ala

Litigatio Satanae contra genus humanum R5a

Llibre de consolació i de consell R24 (Übers./Bearb.)

Llibre del gentil e dels tres savis R32a (Fass.)

Los secrets de Petrarca R56a (Übers./Bearb.)

Lumen curatorum R38

Malogranatum R55

Manipulus curatorum R38

Margarita poetica R56b (Übers./Bearb.)

Mascarón R5b (Übers./Bearb.)

Meditationes R27

Melibeus und Prudentia R24 (Übers./Bearb.)

Meliboeus R24 (Übers./Bearb.)

Mellibeus R24 (Übers./Bearb.)

Ménagier de Paris R24 (Übers./Bearb.)

Mystère de l'Advocacie Nostre Dame R5a (Übers./Bearb.)

Oerloy der ewigher Wijsheit R54 (Übers./Bearb.)

Ordo iudicii inter Christum et Sathanam R19

Passio Christi secundum Anselmum R21

Phantasticus R32t

Pharetra christianorum R26

Pharetra contra Iudaeos R49

Pharetra fidei R26

Pharetra fidei catholicae R26, R26 (Autor), R49

Pharetra fidei christianae R26

Pharetra Iudaeorum R59

Piaito ch'ebbe Dio con l'inimico R7 (Fass./Übers.)

Planctus Mariae et Anselmi de passione Domini R21

Planctus sancti Anselmi R21

Practica magistri Odomari ad discipulum R51

Preparatio lapidis R39

Processus contemplativus quaestionis ventilatae coram domino nostro Jesu Cristo R5c

Processus diaboli contra genus humanum R5b

Processus iudiciarius super possessorio R5a

Processus Satanae R5

Processus Satanae contra genus humanum R5a

Quadraginta quinque conclusiones R72 (Datierung)

Quaestio Christi ad Cain R3

Quaestio valde alta et profunda ad probationem divinae Trinitatis et Incarnationis R32s

Quaestiones inter Christum et diabolum R7

Quaestiones quae fuerunt inter Christum et diabolum R7b 
Quare beata virgo dicta est advocata nostra R5a

Quis dabit A7

Rationale operum divinorum $\mathrm{R} 75 \mathrm{~b}$

Responsio ad Abbreviaturam Communitatis R41

Responsiones ad xliv conclusiones R72 (Datierung)

Responsiones fratris Richardi de Conyngtona ad rationes papales R44

Revelationes factae Richalmo abbate R17

Richalmi abbatis revelationes R17

Richalmi abbatis visiones $\mathrm{R} 17$

Roman de Mahomet et Livre de la loi au Sarrazin R32a (Übers./Bearb.)

Rubrica consolationis et consilii R24

Sacramentale ad utilitatem scolarium R38

Scotichronicon R46 (Übers./Bearb.)

Secreto de Francesco Petrarca R56a (Übers./Bearb.)

Secretum 56a

Serium senectutis R18

Soliloquium de quatuor (mentalibus) exercitiis $\quad$ R27

Somnium viridarii R64, R37 (Übers./Bearb.)

Speculum alchimiae R58

Speculum animae A11

Speculum humanae vitae R61

Speculum mortis R56b (Übers./Bearb.)

Speculum patientiae R61, R61 (Fass.)

Speculum sapientiae R61

Speculum simplicium animarum A4

Summa contra haereticos R13

Summa contra Patarenos R13

Summa de quaestionibus Armenorum R57a

Summa de sacramentis R38

Summa de septem sacramentis R38

Summa quaestionum contra Patarenos R13

Summa summae R66b

Tale of Melibee R24 (Übers./Bearb.)

Thalmoth R59

Thalmut sive disputatio contra Iudaeos R26

The Dialoges of creatures moralysed R48 (Übers./Bearb.)

The Gast of Gy R46 (Übers./Bearb.)

The Seven Poyntes Trewe Wisdom R54 (Übers./Bearb.)

Thesaurus secretus operationum naturalium R39

Tractatulus de custodia castitatis R74b

Tractatulus qui dicitur domesticum scilicet paupertatis R30

Tractatus beati Augustini de passione Domini R6

Tractatus bilogorum R67b

Tractatus consolationis et consilii R24

Tractatus contra haereticos R13

Tractatus contra Iudaeos R26, A9

Tractatus contra Iudaeos nomine Thalamoth R59

Tractatus de advocata nostra beata Maria virgine $\mathrm{R} 5 \mathrm{a}$

Tractatus de frequenti celebratione et salubri communione $\quad$ R75a

Tractatus de Iudaeis R49

Tractatus de morte R63 
Tractatus de quatuor exercitiis R27

Tractatus de sacramentis R38

Tractatus de septem sacramentis R38

Tractatus de statu saeculi R29

Tractatus de triumpho romano R69

Tractatus de virginitate et castitate $\mathrm{R} 74 \mathrm{~b}$

Tractatus disputans contra Iudaeos R49

Tractatus per modum dialogi inter Latinum et Graecum contra errores Graecorum A20

Tractatus perutilis obstruens ora detractorum fratrum ordinis gloriosissimae Dei genitricis Mariae de monte Carmeli R62

Tractatus procuratoris in quo diabolus producit litem coram iudice omnipotente Deo contra genus humanum R5b

Tractatus procuratoris sub nomine diaboli $\mathrm{R} 5 \mathrm{~b}$

Tractatus quaestionis ventilatae coram domino nostro Jesu Cristo R $5 \mathrm{c}$

Tractatus quaestionis ventilatae coram domino nostro Jesu Christo inter virginem Mariam ex una parte et diabolum ex alia parte R5b

Tractatus rationis et conscientiae (de communione) R75a

Tractatus rationis et conscientiae de sumptione corporis Domini R75a

Tractatus super tragoediis componendis R47a

Trialogus R66b

Troost-spieghel in Gheluck ende Ongheluck R56b (Übers./Bearb.)

Turba philosophorum A2

Twispraec der creaturen R48 (Übers./Bearb.)

Violatae pudicitiae narratio R71c

Visio Policarpi R40

Visiones seu revelationes Richalmi abbatis de Speciosa Valle R17

Von der Arz(t)ney bayder Glück des guten und widerwertigen R56b (Übers./ Bearb.) 


\section{Incipit}

Es werden auch die Incipit der Prologe, Epiloge und anderer ausführlicher Paratexte des Verfassers aufgeführt. Falls der Text mit einer kurzenWidmung, einer Grußformel, einem Bibelzitat oder einem Gebet beginnt, findet sich das Incipit sowohl mit dieser Einleitung als auch ohne sie. Bei Dialogen, die mit dem Namen einer Figur als Einleitung eines Redebeitrags anfangen, findet sich das Incipit mit und ohne diesen Namen.

A te Mensurate quero unde primo potestates venerunt $\mathrm{R} 45$

$A b$ intellectuali virtute sophiam theoricam, a morali vero practicam dixerim $\mathrm{R} 47 \mathrm{c}$

Accessit Mascaron [Varianten: Mascharon, Ascaron, Ascharon] ad Dei omnipotentis praesentiam et ait $\mathrm{R} 5 \mathrm{~b}$

Accidit duos homines ad generale Concilium euntes sibi invicem obviasse R32t

Accidit pridie Parisius dominas sex in loco amoenissimo sibi ad invicem obviasse $\mathrm{R} 32 \mathrm{n}$

Accidit quod circa Parisius obviaverunt se ad invicem fidelis et infidelis. Salve dicto ad invicem R32s

Accidit, quod Intellectus et Fides soror sua olim peregrinando ibant simul et ait Intellectus: magna derogatio est $\mathrm{R} 32 \mathrm{k}$

Accidit quod Raimundista et Averroista diu disputaverunt Parisius R32p

Acuens: A te Mensurate quero unde primo potestates venerunt $\mathrm{R} 45$

Acuens: Iussu iudicis a te, Mensurate, quero unde primo potestates venerunt $\mathrm{R} 45$

Acuite sagittas, implete pharetras ad prosternendas vulpeculas, quae demoliuntur vineas nostras $\quad$ R26 ...Ad asilum currit profugus $\mathrm{R} 67 \mathrm{a}$

...Ad hoc ut possimus pervenire ad perfectam scientiam primo expedit scire quatuor esse lapides spiritales R58

Ad Iudaeorum confutationem omnis Christi fidelis tollat pharetram hanc et arcum $\mathrm{R} 49$

Ad probandum autem quod Messias iam venerit $\mathrm{R} 12$

Ad Rolandum. Dum nudiustertius plene meis maeroribus $\mathrm{R} 47 \mathrm{c}$

Advenire te sospitem, Paduane exoptate dudum atque amate, plurimum grator $\mathrm{R} 71 \mathrm{e}$

Aetas florida est, multum superest vitae R56b

Aggrediatur ergo ratio conscientiam utpote minus iuste agentem vel nimis timidam R75a

Ait angelus beatus Michael beato Gabrieli: ponere quod sit bonum et magnum Deum esse $\mathrm{R} 32 \mathrm{u}$ ...Ait Philosophia suspirando et lacrimando R32o

Alithia: Licet dixit insipiens in corde suo, non est Deus, tamen videtur supponendum omni homini Deum esse R66b

Amor. Ecce mihi quaesitus occurris, Geri, angulariter, importune, cupide $\mathrm{R} 42$

Anno Domini MCCC in festo Nativitatis Domini frater Iohannes Gobi ordinis praedicatorum prior in conventu de Alesto $\mathrm{R} 46$

Anselmus. Dic mihi, carissima domina, quale fuit initium passionis filii tui? $\quad$ R21

Antequam Raimundus sive Raimundista et Averroista recessissent a domina Contradictione, dixit Raimundus R32q

Antiqui hostis calliditate callidi superata $\mathrm{R} 2$

Arnoldum Lucam sic intellige. Completis libris naturalibus, medicinalibus et moralibus $\mathrm{R} 28$

Ascendam in Palmam ut apprehendam fructus eius R21

Attonito mihi quidem et saepissime cogitanti R56a

Audite somnium meum quod vidi, Genesis XXXVII capitulo [Gn 37, 6]. Licet scriptum sit non augurabimini R64

Augustinus in libro de fide ad Petrum dicit miraculum est quidquid arduum $\quad \mathrm{R} 46$

Augustinus: Quid agis, homuncio? quid somnias? quid expectas? R56a

...Aures sanctitatis vestrae in cuius sapienti eloquentia $\mathrm{R} 12$

B: Orator secundi electi. Lex iubet, iura sanciunt, ratio testatur R70

Beatus Anselmus episcopus longo tempore cum ieiuniis, lacrimis et orationibus [Variante: cum lacrimis et orationibus et ieiuniis] R21 
Beatus Anselmus longo tempore cum orationibus et ieiuniis [Variante: lacrimis] R21

Beatus Anselmus per singula quaesivit passionem Jesu Christi et beata Maria respondit per singula. Quaesivit ergo sic primo R21

Beatus vir qui non abuit in consilio impiorum et in via etc. $[\mathrm{Ps} 1,1]$ Evangelico viro triplex imponitur malignitas fugienda R41

Catholica veritas dicit quod valde reprehensibiles sunt et puniendi pseudopraedicatores moderni qui sine auctoritate $\mathrm{R} 72$

... Catholicus loquitur: In evangelio Fohannis capite primo: Omnia per ipsum facta sunt R13

Civitas est locus hominum in quo intellectus humanus habituat se ipsum de scientia liberali et mechanica R32x

Claves regni caelorum esse datas a Christo Romano pontifici, id est beato Petro R52

Clericus. Miror, optime miles, paucis diebus tempora mutata, sepultam iustitiam, eversas leges naturales, theologicas, canonicas et civiles R64

Cognitione habita apud daemones de Christo pendente in cruce $\mathrm{R} 7 \mathrm{~b}$

Colligite fragmenta ne pereant [Ioh. 6, 12]. Cum ex debito iniunctae sollicitudinis R16

Compostellae praesul, velle videris honestum/Berengari, mente pari reprobas inhonestum $\mathrm{R} 43$

Concupiscentia: Quis est beatus, quod omnes esse volumus? R34

Contigit quod quidam Iudaeus, qui publice vocabatur Rabi, qui et ipse magister erat Iudaeorum R33

Contigit quod sedens in choro fratrum praedicatorum Avinione septima mensis decembris $\mathrm{R} 79$

Cum apostolus dicat I Cor. XII c. quod ad hoc quod in corpore ecclesie non sit scisma R78

Cum Christus pendebat in cruce, tunc venit daemon $\mathrm{R} 7 \mathrm{a}$

Cum Deus principaliter creaverit hominem $\mathrm{R} 32 \mathrm{~g}$

... Cum Dominus Iesus nostrae redemptionis R3

... Cum ex debito iniunctae sollicitudinis R16

Cum humanum genus post lapsum primorum parentum de paradiso voluptatis $\mathrm{R} 61$

Cum identitas sit mater fastidie [sic] et pulchra alternatio delectat animum R66a

Cum locutio ad personam multis plus complacet quam locutio generalis $\mathrm{R} 66 \mathrm{~b}$

Cum nonnulli perspicue veritatis ignari $\mathrm{R} 47 \mathrm{~b}$

Cum per participationem longi temporis conversationem infidelium $\mathrm{R} 32 \mathrm{a}$

Cum res fortunasque hominum cogito $\mathrm{R} 56 \mathrm{~b}$

Cum Richalmus abbas puerulus esset et in via cum coaetaneis luderet R17

Cum saecularis voluisset ad quaestionem procedere, opposuit se Canonista dicens: Iacobita et saecularis R79

Cum sit beati Hieronymi sententia dicentis: Multi iuxta vetus elogium cum loqui nesciant $\quad$ R74a

Cum tortuosus et callidus ille serpens qui primos parentes de paradiso voluptatis $\mathrm{R} 65 \mathrm{~b}$

Cupiens loqui de conversione, illius gratiam invoco R16

Cur, o caelites, in foedissima parte temporum sub adverso sidere R73

Da Domine in te credentibus affectum $\mathrm{R} 32 \mathrm{n}$

Daemon: Scisne actorem me esse, te reum cum caeteris, hunc iudicem ab omni principe delegatum R28

Damon. Interfuisses historiae, quam nuper audivi, ita pudicitiae pretio affectus esses R71c

Datus in socium itineris et laboris patri cuidam [auch: cuidam patri] limitatorio R53

De apprehensione ac apprehensionis modis seu diversitatibus disserens, disputationis seriem per dialogum prosecutus sum R35

De trinitate Iudaeus arguit: Vos christiani tenore [sic] creditis dicentes Deum esse trinum $\mathrm{R} 49$

Descendit prius ad inferiores partes terrae [Eph. 4,9]. Cum Dominus Iesus nostrae redemptionis R3

Detractor. Tu qui de antiquitate iactas eam proba, fertur enim Aristoteles cum videret libros Moysi dixisse R62

Deus aeterne, cuius natura bonitas et opus misericordia est, qui etiam cum iratus fueris R8

Dic mihi, carissima domina, quale fuit initium passionis filii tui? R21 
Dic primo numquid dominus noster Fesus, sicut pauperiem artissimam in sexto libro operis tui descriptam R57b

Dic, quaeso, o homo, si post devotam invocationem $\mathrm{R} 27$

Dicit Graecus Saraceno: quo certius demonstratur distinctio divinarum Personarum R32b

Dicitur quod quidam homo christianus arabicus, cuius nomen erat Raimundus, qui diu laboravit R321

Dico maiorem Deum illum qui est ens reale et necessarium $\mathrm{R} 32 \mathrm{w}$

Dictum est in tertio paragrapho sacramenti altaris R32w

Dilectissimo domino suo et patri in Christo Stephano Dei gratia Cantuariensi archiepiscopo et totius Angliae primati et sanctae Romanae ecclesiae cardinali Petrus servus eius devotus et prior sanctae Trinitatis Londoniae dictus (...) Aures sanctitatis vestrae in cuius sapienti eloquentia $\quad \mathrm{R} 12$

Discipulus. Quoniam occasione dissensionis quam in Christianitate conspicio $\quad$ R52

Discipulus. Romani iura imperii non iura sed iniuriae et iniustitiae $\quad$ R52

Discipulus. Salomonis utcumque sequendo vestigia R52

Discipulus. Scripturae divinae Romanos pro tempore R52

Divina gratia quidam homo pauper culpabilis $\mathrm{R} 32 \mathrm{~b}$

Divina ordinatione contigit quod in quadam terra fuerit homo quidam gentilis valde peritus in philosophicis scientiis $\mathrm{R} 32 \mathrm{a}$

Dixit Catholicus Infideli: Suppono quod Deus sit ens reale et hanc positionem probo sic $\quad$ R32e

Dixit eremita: Illud esse, quod non est definibile, non est demonstrabile R32v'

Dixit Saracenus: Deus altus et sublimis septem habet conditiones sibi essentiales R321

Domino Francisco de Barbarino, iuris civilis professori. R42

Dudum felicis recordationis dominus Clemens $\mathrm{R} 57 \mathrm{~b}$

Dum nudiustertius plene meis maeroribus $\mathrm{R} 47 \mathrm{c}$

Dum variat studiosus homo sacra coniugiorum/foedera felici foedere crebro caret R18

Duo viri mirae sapientiae, quorum unus Iudaeus alter Christianus erat, inhabitabant in quadam nobili civitate $\mathrm{R} 32 \mathrm{c}$

Egisse mecum nimis illiberaliter naturam queror $\mathrm{R} 56 \mathrm{~b}$

Es tu fidelis? Sum domine. R36

Est negotium mutum, aptum et adoptabile, nec non valde salutare tractare modum $\mathrm{R} 32 \mathrm{~d}$

Est quidam frater bonae, non audeo dicere, conversationis, cum adhuc vivat $\mathrm{R} 17$

Et dabo tibi mustum malorum granatorum meorum. Can VIII [Ct 8, 2]. Spiritus Sanctus sua benigna R55

... Evangelico viro triplex imponitur malignitas fugienda $\mathrm{R} 41$

Ex eo tempore quo ficus floruit sub quo Natanahel latuit, coepit exordium miseriae matris Iudaeorum synagogae R25

Ex omnibus quae vel mihi lecta placuerint vel audita R56b

Executio: Exulabis. Timor loquitur: Exulabis. Mens: Sollertiae causas captabo, qui remissus atque hebes iam domesticis otiis marcueram. $\mathrm{R} 47 \mathrm{c}$

Exsurge Deus, iudica causam tuam [Ps 73, 22]. Catholicus loquitur: In evangelio Fohannis capite primo: Omnia per ipsum facta sunt $\mathrm{R} 13$

Fervet animus te videndi desiderio, pater alme R60

Fili, accedens ad servitutem Dei sta in iustitia et timore et praepara animam tuam ad temptationem R55

Flecto genua mea [Eph 3,14] ad dominum et patrem meum, Pontificem Summum et vicarium Domini nostri Jesu Christi in terra, humiliter obsecrans, sicut pauper R44

Flecto genua mea ad Patrem Domini nostri Fesu Christi [Eph 3,14] R27

Fuit unus vir illustris quem in civitate Parisiensi R51

Fuit unus vir in omnibus illustris ex genere R51

Fuit vir quidam moribus illustris et genere R51

Fuit vir unus moribus et genere illustris R51 
Fuit vir unus moribus illustris R51

Fuit, fuit quondam in hac republica virtus, quam velut quaedam coeli luminaria R9

Galba: Quod te nunc otium, Cato, sequestrem haec inter frondentia tenet? R71b

Genius, magni Iovis vicarius vasta superiorum culmina regnorum $\mathrm{R} 70$

Gloriosissimo et sincerissima caritate venerando domino, Philippo illustrissimo R32n

Gloriosus inclitus miles ille militum parum dixi $<t>$ : Coronator omnium recte militantium $\mathrm{R} 19$

Haereticus: Quomodo potest hoc esse, quod panis aut vinum convertatur in corpus Christi aut sanguinem? R14

Hanc amavi et exquisivi a iuventute mea et quaesivi mihi sponsam assumere. Erat quidem iuvenis Deo notus R54

Heu, heu me fili miserum morte tua R71d

Hinc est quod cum R78

Homo: Usque quo clamabo, Domine, et non exaudies, vociferabor impatiens et non salvabis? [Hab 1,2] Si fas est igitur, Dei patris eternum verbum, sermo meus ad te currit R67b

Hortor autem unumquemque legentem ut non abhorreat asperitate et duritiis verborum R78

Iesu Christe gloriose in quo universi creati nobilitas ac perfectio $\mathrm{R} 79$

Immo contumacies [sic] non possint R71d

In Dei nomine amen. Ut ad perfectam scientiam pervenire possimus primo expedit [Variante: oportet] scire R58

In hoc libro loquar de secretis naturae R39

In nomine Patris et Filii et Spiritus Sancti. Amen. Venerabilium gesta patrum dignosque memoria titulos antiquorum studio pietatis annalibus commendare $\mathrm{R} 23$

In nomine sanctae et individuae Trinitatis amen. Ad hoc ut possimus pervenire ad perfectam scientiam primo expedit scire quatuor esse lapides spiritales R58

In nomine sanctae et individuae Trinitatis amen. Ut ad perfectam scientiam pervenire possimus $\mathrm{R} 58$

In omnibus curiosus existis nec me desinis R52

... In primis potest Fudaeus interrogare dicendo: Domine, ego nimis admiror cur nos christiani tantum odiunt [sic] R1

In quadam magna silva sub umbra cuiusdam pulchrae arboris iuxta magnum fontem $\mathrm{R} 32 \mathrm{~g}$

In quadam silva iuxta Parisius stabat Raimundus tristis et desolatus iuxta quendam fontem, considerans et studens $\mathrm{R} 32 \mathrm{~h}$

In quodam prato iuxta Parisius $\mathrm{R} 32 \mathrm{j}$

In scholis nostris iocoso quodam incidente litigio de nobilitate $\quad \mathrm{R} 20$

In una magna silva abundosa arboribus, fontibus, pratis et valde amoena $\mathrm{R} 32 \mathrm{w}$

Incipiens igitur vicarius sic alloqui sub his verbis ipsum aggreditur: Quis diabolus vos fratres adinvenit et coartat nobis curatis R53

Incipit primus liber de Creatore et ad ipsum pertinentibus. Introducatur ergo anima ad interrogandum spiritum, ut primo dicat: $O$ clarissime spiritus $\mathrm{R} 31$

... infinita et illa ab aliquo R4

Inimicus domesticus paupertatis dicit: Non solum divitiis temporalibus renuntiavi R30

Inquit Lovatus: Tragediae cuiusque subiectum est eversi regni cuiuspiam sub deploratione descriptio. R47a

Interfuisses historiae, quam nuper audivi, ita pudicitiae pretio affectus esses $\mathrm{R} 7 \mathrm{lc}$

Interpellasti me, dum persaepe in diversoriis $\mathrm{R} 47 \mathrm{a}$

Interrogatio seu quaestio prima. In primis potest fudaeus interrogare dicendo: Domine, ego nimis admiror cur nos christiani tantum odiunt [sic] $\mathrm{R} 1$

... Introducatur ergo anima ad interrogandum spiritum, ut primo dicat: $O$ clarissime spiritus $\quad \mathrm{R} 31$

$<$ I>nvictissimi patres conscripti, in quibus ecclesiastica salus pendet $\mathrm{R} 69$

Ioh.: Cur, o caelites, in foedissima parte temporum sub adverso sidere $\mathrm{R} 73$

Iohannes: Dic primo numquid dominus noster fesus, sicut pauperiem artissimam in sexto libro operis tui descriptam $\mathrm{R} 57 \mathrm{~b}$ 
Iohannes: Quia circa rerum propter hominem creatarum inferius in hoc mundo dominium, proprietatem, possessionem, ius utendi et usum R57b

Iohannes: Quia ex litterali sensu scripturae sacrae intendis in hoc opere tractare Armenorum propositas quaestiones ostende mihi R57a

Iohannes: Quid agimus, Littera? Merendone tabescemus quod dominum, quod patrem, quod columen unicum spei nostrae procul miserimus? R71a

Iussu iudicis a te, Mensurate, quero unde primo potestates venerunt $\mathrm{R} 45$

Iudaeus dicit: Vos christiani credentes dicitis temere [Variante: temere dicitis] Deum esse trinum R49

Iudaeus dicit: Vos Christiani temere creditis Deum esse trinum et unum, nos autem scimus unum esse Deum R59

Iudaeus dicit: Vos christiani temere creditis quod dicitis Deum esse trinum $\quad \mathrm{R} 49$

Kalodemonum angelorum et bonorum pacem Christifidelium zelantium R68

Legitur in libro Regum quod rex Assuerus, spreta regina Vasthi, Esther elegerit in reginam R59

... Lex iubet, iura sanciunt, ratio testatur R70

Liber iste factus fuit hac intentione, videlicet quod christianus et Saracenus per rationes et non per auctoritates ad invicem disputarent R32l

Licet characterem, quo ego insignitus sum, tu non geras nec acceperis $\mathrm{R} 1 \mathrm{l}$

... Licet scriptum sit non augurabimini R64

Maestus: Heu, heu me fili miserum morte tua R71d

(Magister) In omnibus curiosus existis nec me desinis $\mathrm{R} 52$

Magister, quid faciendo vitam aeternam possidebo? [Lc 10, 25] Dicit fesus: Mandata nosti, hoc fac et vives. Quorum primum et maximum: "diliges Dominum tuum verum" R29

Magister: Semper quidem, frater dulcissime [Variante: dilectissime], ut nosti, delectatus sum cum tua dilectione $\mathrm{R} 74 \mathrm{~b}$

Magister unus quidam nomine Policarpus [Variante: Porphinius] in Hibernia R40

... Magni sudoris plenam periculis R75b

Miror, optime miles, paucis diebus tempora mutata, sepultam iustitiam, eversas leges naturales, theologicas, canonicas et civiles R64

Multas frequenter, princeps illustrissime, vestrae magnificentiae tam humilis devotaque conversatio cordi meo intulit R74a

Multifarie multisque modis olim Deus immensae potentiam maiestatis et divitias gloriae sue manifestans R23

Multorum tam clericorum quam laicorum querela est $\mathrm{R} 75 \mathrm{a}$

Mundus. Cum vicio nuper proprio caro victa pateret,/iratum, nec mente ratum cor ad ima moveret R43

Narrabo vobis mirabilia magna R40

Narrator: Multifarie multisque modis olim Deus immensae potentiam maiestatis et divitias gloriae sue manifestans R23

Nostis fratres qualiter Satanas subintrans viscera fudae R5a

Nostis fratres carissimi, inquit Sathanas, proditoris misteria Iudae procuravit $\mathrm{R} 5 \mathrm{c}$

Nostis fratres Sathanas proditoria ministeria inde procuravit $\mathrm{R} 5 \mathrm{c}$

Nostis fratres carissime qualiter Sathanas proditoria misteria inde procuravit $\mathrm{R} 5 \mathrm{c}$

Nota quod quidam magister nomine Policarpus R40

Notandum quod beatus Anselmus longo tempore cum lacrimis R21

...Nova lux visa est cunctis Christi fidelibus suboriri R45

O animae fideles sponsae Iesu Christi fletum deducite donec sponsus R6

O insensati, quis vos fascinavit non credere veritati! Cedrus alta Libani conformatur hyssopo $\mathrm{R} 76$

Omnis arbor bona R21 
Omnis reverentiae et sanctitatis cultu dignissimo patri domino Thomae, titulato Sanctorum Nerei, Archilei atque Pancracii presbytero cardinali beatissimo, integra subiectione devotissimus servus et affectu plenissimus filius. R7 la

Orator secundi electi. Lex iubet, iura sanciunt, ratio testatur $\quad \mathrm{R} 70$

P<hilosophia>: Quid a me discere cupis? $D<$ iscipulus $>$ : De apprehensione inquam doceri desidero R35

Parisius fuit magna contrarietas inter Raimundum et Averroistam, qui philosophice disputabant et maxime super quinque quaestionibus $\mathrm{R} 32 \mathrm{~m}$

Parisius Raimundista et Averroista disputabant. Raimundista dicebat, quod Deus est efficiens $\mathrm{R} 32 \mathrm{r}$

Pater examinans filium quaerit: Vellem declarari, quomodo Deus omnia bene fecerit et qualiter omnia R75b

Peccator (ad Deum). Deus aeterne, cuius natura bonitas et opus misericordia est, qui etiam cum iratus fueris R8

...per gratiam sitire iustitiam donec hauriat aquas in gaudio de fontibus Salvatoris R57a

Per unam magnam silvam ibat Raimundus tristis et deconsolatus $\mathrm{R} 32 \mathrm{v}$

Petrus. Reverende magister et domine prout auribus meis crebra relatione, proh dolor $\mathrm{R} 65 \mathrm{a}$

Petrus: Cum tortuosus et callidus ille serpens qui primos parentes de paradiso voluptatis R65b

Praecedit actus meritorius ut succedat R41

Primo proponit clericus miramentum quodammodo sub hac forma. Clericus: Miror, optime miles, paucis diebus tempora mutata R37

Primus articulus: quod Raimundus Lul dogma suum non habuit per hominem R76

Princeps ergo illustrissimus prae caeteris pugil Ecclesiae, cum ut in Prohemio superius recitavi R64

Principum illustrissimo ac Francorum serenissimo regi $\mathrm{R} 32 \mathrm{o}$

Procurator (itaque) legitime constitutus, astutus et versutus ad praesentiam Christi accedens dixit R5a

Procurator legitime constitutus et assuetus ad praesentiam Christi accedens dixit $\mathrm{R} 5 \mathrm{c}$

Propter iniquitatem corripuisti hominem et quasi de sublimo in inferno dimersisti R77

Propter iniquitatem corripuit Deus hominem et quasi de limo [sic] in infernum dimersit $\mathrm{R} 77$

Quadam die convenimus ad insimul colloquendum $\mathrm{R} 17$

Quadraginta quinque conclusionibus meis catholicis nuper scriptis et prout materia fidei $\mathrm{R} 72$

Quacunque scripta sunt ad nostram doctrinam scripta sunt R61

Quaerunt philosophi et magistri, qui convenerunt, ut mortem describerent et ostenderent, quid sit mors R63

Quaestiones, definitiones, laudes, orationes et intentiones sunt huius operis fundamenta $\mathrm{R} 32 \mathrm{f}$

Quamquam illustribus iamdudum pateat exemplis R71c

Quia circa rerum propter hominem creatarum inferius in hoc mundo dominium, proprietatem, possessionem, ius utendi et usum R57b

Quia cum septem libellos de pauperie Salvatoris composui de mendicitate $\mathrm{R} 57 \mathrm{~b}$

Quia ex litterali sensu scripturae sacrae intendis in hoc opere tractare Armenorum propositas quaestiones ostende mihi R57a

Quia pius et misericors Deus, carissimi fratres [Variante: fratres carissimi], permittit R8

Quicumque hoc opusculo et caetera verba sunt folio $\mathrm{R} 17$

Quid a me discere cupis?'D<iscipulus>: De apprehensione inquam doceri desidero R35

Quid agimus, Littera? Merendone tabescemus quod dominum, quod patrem, quod columen unicum spei nostrae procul miserimus? R7la

Quid agis, homuncio? quid somnias? quid expectas? R56a

Quidam de praedestinatione divina male sentientes, dicunt quod quidam homines ex necessitate salvabuntur R15

Quidam iuvenis, Melibeus nomine, vir potens et dives $\mathrm{R} 24$

Quidam Melibeus nomine iuvenis potens vir R24 
Quidam Tartarus habitans in finibus Saracenorum valde sapiens et eruditus in Philosophia R32d Quis est beatus, quod omnes esse volumus? R34

Quo Lugi et Conselicis oppida Marchioni eventu subducta forent R71b

Quod te nunc otium, Cato, sequestrem haec inter frondentia tenet? R71b

Quod verbis vituperii satis abundas per tuum responsum experiar evidenter, sed quaeso rationi clare respondeas $\mathrm{R} 50$

Quomodo anima per mentale exercitium debeat radium contemplationis reflectere ad interiora sua ... Dic, quaeso, o homo, si post devotam invocationem R27

Quomodo potest hoc esse, quod panis aut vinum convertatur in corpus Christi aut sanguinem? R14

Quoniam certum dignoscitur apud illum esse impetrandum auxilium...Ait Philosophia suspirando et lacrimando $\mathrm{R} 32 \mathrm{o}$

Quoniam in divinis eloquiis copiosissime spiritualis laetitia invenitur asserente propheta [Ps. 118, 162]: Laetabor ego super eloquia tua R31

Quoniam me saepius rogasti, Petre, postquam sacerdotii sacrum ordinem suscepisti, ut aliqua te de administratione sacramentorum edocerem R38

Quoniam multi sunt, qui in adversitatibus et tribulationibus taliter affliguntur R24

Quoniam occasione dissensionis quam in Christianitate conspicio R52

Quoniam omnis res per divisiones dilucidius aperitur $\mathrm{R} 22$

Quoniam secundum apostolum quaecunque scripta sunt ad nostram doctrinam scripta sunt $[\mathrm{Rm}$ 15,4] R61

Quoniam ut dicit beatus Augustinus in libro de fide ad Petrum miraculum est quidquid arduum aut insolitum R46

Quoniam ut dicit Seneca communis mos [Variante: vox] naturae est, quod omnes appetimus esse beati R34

Raimundus iacens in lecto suo volens se condormire $\mathrm{R} 32 \mathrm{u}$

Raymundus ait Petro: Quid est fortuna quam maledixisti? R32j

Raymundus indignus servus eius et insufficiens procurator infidelium supplicat $\mathrm{R} 32 \mathrm{e}$

Raymundus Parisiis studens et considerans perversum statum mundi R32i

Recitatur quod duae dominae, quarum unius est nomen Laus et altera Oratio nominatur, in quadam via maxima $\mathrm{R} 32 \mathrm{f}$

Regis serenissime potestatis excelsae $\mathrm{R} 32 \mathrm{q}$

Relaxationis defensio: Beatus qui intelligit super egenum et pauperem, Psalmus [Ps 40, 2]. Praecedit actus meritorius ut succedat $\mathrm{R} 41$

Remanserunt autem in castris duo viri quorum unus vocabatur Heldad et alter Medad super quos requievit spiritus. Numerorum XI. [Nm 11, 27] Dum iuxta stratum meum nocturno tempore $\mathrm{R} 45$

Respondit Raymundus dicens: quod Theologia sit scientia duobus modis, scilicet appropriate et proprie R32i

Restat finaliter perstringere totam istam sententiam cum quodam epilogo R66a

Revelationes istae factae sunt carissimo, ac familiarissimo meo beatae memoriae abbati Richalmo R17

Reverende magister et domine prout auribus meis crebra relatione, proh dolor $\mathrm{R} 65 \mathrm{a}$

Reverendis in Christo patribus Versi archiepiscopo Manasgardensi ac fratri Iohanni electo Clatensi Maioris Armenie Richardus Radulphus archiepiscopus Armacanus Hiberniae primas, per gratiam sitire iustitiam donec hauriat aquas in gaudio de fontibus Salvatoris R57a

Reverendissimo in Christo patri et d. d. B<artolomaeo Mezzavacca> tit. S. Martini in Montibus R78

Reverendo in Christo patri domino Henrico episcopo Wormiensi [sic] suus Matthaeus facere bona et recipere mala bene. Magni sudoris plenam periculis $\mathrm{R} 75 \mathrm{~b}$

Reverendo in Cristo patri domino Iohanni Olomucensi episcopo, sacrae theologiae speculatori profundissimo et consanguineo nostro carissimo, orationum supplices preces cum submissione condigna et salute. Ad asilum currit profugus $\mathrm{R} 67 \mathrm{a}$ 
Rogatus igitur humiliter et deposcens aquam sapientiae salutaris R68

Roma: Sponsum habeo. Francia: Immo adulterum. Roma: Quare? Francia: Probo. R69

Romani iura imperii non iura sed iniuriae et iniustitiae $\quad$ R52

Salomonis utcumque sequendo vestigia R52

... Sacrae theologiae doctorum et utriusque iuris professorum sententïs veridicis R76

Sanctissimi patres conscripti... siehe $<I>$ nvictissimi patres conscripti...

Sanctissimo et beatissimo in Christo patri et domino, domino nostro, domino Clementi,... Sacrae theologiae doctorum et utriusque iuris professorum sententiis veridicis $\mathrm{R} 76$

Sanctissimo in Christo patri ac domino, domino nostro Innocentio... Dudum felicis recordationis dominus Clemens R57b

Sanctissimo in Christo patri ac reverendissimo domino, domino Iohanni divina providentia sacrosanctae Romanae R45

Sanctus Anselmus longo tempore cum ieiuniis, lacrimis et orationibus [Varianten: cum lacrimis et orationibus; cum lacrimis et orationibus ac ieiuniis; cum orationibus et ieiunïs; cum lacrimis $] \quad$ R21

Scimus, fratres, quod diversa opinio ex Iudaeis R49

Scisne actorem me esse, te reum cum caeteris, hunc iudicem ab omni principe delegatum R28

Scito, fili, quod lapis noster, ut dixit Hermes, est de animata re R39

Scito, fili, quod in hoc libro loquar de secretis naturae R39

Scripturae divinae Romanos pro tempore R52

Semper quidem, frater dulcissime [Variante: dilectissime], ut nosti, delectatus sum cum tua dilectione $\mathrm{R} 74 \mathrm{~b}$

Sentite de Domino in bonitate et in simplicitate R54

... Si fas est igitur, Dei patris eternum verbum, sermo meus ad te currit $\mathrm{R} 67 \mathrm{~b}$

Si vellet aliquis doctus presbyter disputare cum docto Iudaeo, hunc praemunire volo de multis quaestionibus Iudaeorum, et quomodo ad ipsas debeat respondere, secundum posse meum et sicut mihi donavit gratia Salvatoris. R1

Sicut dicit beatus Augustinus in libro de fide ad Petrum miraculum quidquid arduum sed insolitum R46

Sicut ex palea granum et de saxo extrahimus aquam R48

Sol est secundum philosophum oculus mundi, iocunditas Dei [Variante: coeli], pulchritudo～R48

... Spiritus sanctus sua benigna R55

Sponsum habeo. Francia: Immo adulterum. Roma: Quare? Francia: Probo. R69

Sua prima ratio fuit, quod cum visione clara sanctorum non stat spes $\quad$ R52

Theologorum studia ianuam scientiae sibi cupientium aperire debent $\mathrm{R} 32 \mathrm{k}$

Tibi laus, tibi gloria, tibi gratiarum actio, Iesu piissime R57a

Totius sanctimoniae puritate et praeeminenti scientia vir insignis, felicis recordationis, Petrus, cantor Parisiensis R10

Tres tribus ex causis theatrales oderunt sollemnitates $\mathrm{R} 9$

Tu qui de antiquitate iactas eam proba, fertur enim Aristoteles cum videret libros Moysi dixisse $\mathrm{R} 62$

Ubicunque in isto tractatu quidam frater, vel quisam senex ponitur $\mathrm{R} 17$

Universis Christi fidelibus praesentis opusculi seriem inspecturis $\mathrm{R} 65 \mathrm{~b}$

Unusquisque fidelis, prout divisit [in einigen Hss.: divisit sibi] Deus mensuram fidei in illos haereticos debet insurgere $\mathrm{R} 13$

Ut ad perfectam scientiam peruenire possimus primum oportet [Variante: expedit] scire quod tres Lapides et tres Sales sunt R58

Ut attestatur b. Gregorius lib. Pastoral. c. 3, nemo amplius in ecclesia nocet R78

...Venerabilium gesta patrum dignosque memoria titulos antiquorum studio pietatis annalibus commendare R23

Venetus: Advenire te sospitem, Paduane exoptate dudum atque amate, plurimum grator $\mathrm{R} 71 \mathrm{e}$ 
Venit in manus meas libellus visionum abbatis Richalmi corrupte scriptus et incorrectus $\quad \mathrm{R} 17$

Venite ad scolas meas ego narrabo vobis omnia mirabilia multa et infinita ut credatis pietati et fortitudini meae $\mathrm{R} 40$

Venite ad scolas meas. Narrabo mirabilia vobis, ut credatis fortitudinem meam $\mathrm{R} 40$

Venite ad scolas meas narrabo vobis mirabilia magna ut credatis fortitudini meae $\mathrm{R} 40$

$<V>$ erba exhortationis ex tuo ore, o pater, ad me directa animae meae multum salubria cordis mei aure libens suscipio R55

Verba oris eius iniquitas et dolus, ait psalmista [Ps 35,4] per spiritum praevidens prophetice R52

Vergente ad occiduum mundo et instantibus periculosis temporibus, quibus multi R13

Vergente mundo ad occiduum R13

Vetustae religionis Carmeli montis, et Beatae Dei Genitricis Mariae Virginis R62

Videns itaque diabolus suam tirannidem expirasse quam diu in hominem exercuerat R2

Videtur mihi quod sit praesumptio et stultitia quia vos qui estis pueri studetis in sacra scriptura R36

Virgo quaedam venusta facie decoroque aspectu ascendebat a Ierico R26

Viris elegantissimis, magni Caesaris domesticis, sensu et moribus praedotatis dominis magistris Petro de Vinea et Taddeo de Suessa magistri T. animi devotionem R20

Virorum dinoscitur sapientum hunc esse morem $\mathrm{R} 74 \mathrm{~b}$

Vivit quidam magister Polycarpus nomine de Umbria R40

Vix ego quidem talia fine praedestinato praecluderam, cum consors meus R18 


\section{Explicit}

Es werden auch die Explicit der Prologe, Epiloge und anderer ausführlicher Paratexte des Verfassers aufgelistet. Die Explicit sind rückläufig alphabetisch geordnet. Dafür wurden abschließende Formeln oder Kürzel wie amen, explicit, et caetera, Deo gratias nicht berücksichtigt. Falls sich ein Schlussgebet oder eine Datumsangabe abtrennen lässt, wird das Explicit sowohl mit dieser Schlussformel als auch ohne sie aufgeführt.

Paduanus: Tuo parerem arbitratu nisi procedere iuberet. Bene vale. Venetiis anno Domini MCCCCIIII. R71e

...evidenter apparet quod abusus huiusmodi non est haeresis ablatione temporalia [sic] punienda $\mathrm{R} 65 \mathrm{a}$

...vitam emenda $\mathrm{R} 40$

... Vae mihi quia tacui $[\mathrm{Is} 6,5]$ et vae, Domine, tacentibus de te quoniam loquaces multi facti sunt [Aug. conf. 1, 4]. Ad te ergo, Domine Jesu dulcissime, dirigantur verba mea. R30

... Quod ergo tibi placet interroga R52

... Quia sic est intellectus et sophia R51

...utilia legentibus et audientibus delectabilia $\mathrm{R} 48$

...et cum traho hominem traho omnia $\mathrm{R} 7 \mathrm{~b}$

...pudore reticendi dictare quidcumque in buccina venerit haec illa. $\mathrm{R} 74 \mathrm{~b}$

...quasi dicitur nulla $\mathrm{R} 61$

...virgo praeclara, memor esto mei apud filium tuum cum quo tibi laus est et gloria in saecula. R6

...et inhabitare digneris, iuxta sanctum et ineffabile tuum promissum, qui es benedictus in saecula $\mathrm{R} 8$

... donec intrem in gaudio Dei mei, qui est trinus et unus benedictus in saecula. $\quad$ R27

... interrogantur, unicuique dat cuilibet proprium idioma R46

...et erat feria sexta magna $\mathrm{R} 21$

... regnat in trinitate persona. $\mathrm{R} 32 \mathrm{n}$

Littera: En pergo. Tu prosperum interim mihi iter, faustum deinde successum ac reditum superos ora R7la

...dolens retinens meliora $\mathrm{R} 71 \mathrm{~d}$

... quae Anselmo a beata virgine fuit enarrata. R21

... sapientia increata in saeculum saeculi benedicta. R61

...factus sum violator promissionis meae. $\mathrm{R} 17$

... non scientaliter erravi, cum sim verus catholicus. Et ideo submitto istum librum et alios omnes quos feci ad correctionem sanctae ecclesiae Romanae. R32w

... sed divinae capax gratiae fides adsit credula disciplinae $\mathrm{R} 23$

... et merito nam res faciliter deinde [?] in naturam revertitur xxxv di. Ab exordio divinae [irrtümlich für humanae] R69

...et tibi quae parvulus doces ac viris probatissimis quorum rationes et sententiae sunt in medio disputationis prolatae. R35

... sicut novellae olivarum in circuitu mensae Domini saciabimur, apparente nobis gloria fructus ventris virginis benedictae $\mathrm{R} 77$

...cum correctione et emendatione Ecclesiae Sacrosanctae R79

...ut te amando et diligendo disputationem incipiat saecularis et Iacobitae R79

... qualiter tu fateris de sectis <ali>quas reprobas, quod ex gratia primi abbatis ad religionem Christi finaliter sunt acceptae R72

....aut compatiebantur toto corde $\mathrm{R} 21$

Littera: En pergo. Tu prosperum interim mihi iter, faustum deinde successum ac reditum superos ora. Vale. R7la

Accelerant, discedunt, remaneo. Tu peroptime [Varianten: peropportune, perpetue] vale. $\mathrm{R} 60$ 
Paduanus: Tuo parerem arbitratu nisi procedere iuberet. Bene vale R71e

... esset divisus et compositus quod est impossibile. R32q

...cum Patre tuo ac Spiritu Sancto tuo vivus est Deus omnipotens vivens et imperans sine fine. R57a

...et aliis, quot saluti populi christiani utilius invenerit ordinare $\mathrm{R} 57 \mathrm{~b}$

...et ipsorum per modum dialogi machinamenta frivola confutare R62

... seu quovis alio nomine placito baptizare $\mathrm{R} 75 \mathrm{~b}$

... sed nos ad narrationem opportet accingere. R17

Iudaeus respondit ultimo: conducat nos per viam iustitiae ut veritatem valeamus percipere $\quad \mathrm{R} 49$

...ut potens sit exortari in doctrina sana et eos qui contradicunt arguere R36

...et aliis praeficiendo ad praedicta leviter pervenire. R24

...Iudex. Ergo ne in quaestionis principio incipi<a $>$ tis protervire $\mathrm{R} 45$

Vertice purpureo sacro qui in cardine mundi /fulge, Thoma, tui pueri dignare volumen./Quamquam te resonet totum tua fama per orbem, /hoc quoque venturis nostro discere labore. R7 la

... aethereus rex ipse deus digneris adesse. $\mathrm{R} 43$

...et maxime debes exercitare te. $\mathrm{R} 21$

...et ideo quaestiones et instantias filiali, responsiones vero paterna dignetur recipere pietate. $\mathrm{R} 75 \mathrm{~b}$

... in isto ordine sancto sine fine quievit plenus omni sanctitate $\mathrm{R} 40$

...et sic in sancta oratione quievit plenus omni sanctitate $\mathrm{R} 40$

... ut veritati fructuose consentiant in hac parte $\mathrm{R} 66 \mathrm{a}$

... spes nostra salve. R5a, R5b, R5c

... sintque cum rege et intrante et egrediente. Unxit quoque foada pontifex [2 Par 6, 7, 11] ibi. R37

...et incomperta quae Dominus contulisset sibi. R17

... ab illis qui hoc considerabant attentius manifeste poterat comprehendi. R10

... poenitentiam non agam super hoc quod locutus sum facere ei. $\quad$ R26

... filio eius et compatiebantur ei R21

...ut in conspectu sublimis Dei fieret magis gratus. Qui scripsit et composuit dictamen huius libri et qui hunc librum legerit et inspexerit sit gratus et placabilis in gloria summi Dei et praeservetur in hoc saeculo ab itineribus per quae vadunt ad ignem inferni illi, qui sunt in ira iustitiae summi Dei. R32a

...et ut essent in una fide, credendo in Sancta Trinitatem nostri Domini Dei. R32b

... donec intrem in gaudio Dei mei R27

... contra omnes antiqui hostis insidias accingi R61

... dolens retinens meliora. M CCCCI VIII kalendarum Octobrium Patavii $\quad \mathrm{R} 71 \mathrm{~d}$

... stat pro signo de subveniendo sodali R62

... incremento diutissime gratulari. R32o

...et adiuvet a praeclarissimis virtutibus tot et tanta vitia superari. R28

...ut iste labor vobis et aliis prosit ut potui devotius exorari [Varianten: eroravi, exoravi, exaravi]. R74a

... doctos studere fieri, non arroganter velle videri. $\mathrm{R} 32 \mathrm{n}$

... hunc componi tractatum, ipsum accelera exordiri R52

... Si autem nihil talium, ut confido, immensas laudes summo refero Creatori, bonorum omnium largitori R76

...et beatissime iungat Ecclesiae triumphanti. R64

... eorum ligamina dissolvendo illius gratiae interventu, cuius non sum dignus ut solvam eius corrigiam calciamenti R50

... ad quam consequendam pro viatico datum est nobis corpus Domini nostri Iesu Christi R75a

... Vicarius. De caetero nolo tecum in materia litigï conferre sed ad praesens alia facturus a te recedo et ideo vale frater sicut valere meruisti R53

... ipsorum dicta praesenti scripto commendavi $\mathrm{R} 53$

...ut iste labor vobis et aliis prosit ut potui devotius exoravi [Varianten: eroravi, exorari, exaravi]. R74a 
Modo intelligas quoniam dicimus aut quoniam facimus nostram sublimationem, quod separemus partes quae elevantur in altum ab illa [sic] que remanent desubter, immo volumus quod ambo maneant in simul R58

...probitatem modis omnibus esse nobilitati generis praeferendam. $\quad \mathrm{R} 20$

... quae et haec plenitudine tuae auctoritatis effundam. R47a

Sed nunc illum ego seriosius, summissiore stilo, sed prolixiori confutatione, repellam $\mathrm{R} 47 \mathrm{C}$

... sequere felicem matrem, quae septem suos filios ad cognitionem Christi animavit per martyrii palmam R61

...omnia corpora, quae tangit, ducit ad verissimum Solaris complementum et super omnia corpora Lunam. R58

...et de hoc sum certus, quia ego ibi eram. R321

... atque ecclesiam verisimiliter suam temporalitatem, modo ut praemisi, perdituram $\mathrm{R} 70$

... remansit caelestis militia cum gaudio ingenti laudans advocatam R5a, R5b, R5c

... lenemque vitam fore, si vincerentur, iniustam et confragosam, victoribus quoque vitam veram et beatam. R28

...et credo verum quod ipsa duxit statuendum in una Extravaganti quae incipit Unam sanctam. $\mathrm{R} 64$

Ut renuant variata modo convivere vili, /et valide studeant validam producere vitam. $\mathrm{R} 18$

... Quod si adhuc reprehendat adhuc utique virginitatem nuptiis praeferam, quam diu vivam $\mathrm{R} 74 \mathrm{~b}$

... sese offerebat cunctis affabilitate praestabilem. $\mathrm{R} 9$

... Inspiret vobis Deus hoc facere, quod magis erit ad imitationem vitae evangelicae et sacrosanctae matris Ecclesiae promotionem et meam conscientiae assecurationem et serenationem. R44

...cum sis christianus; ad quod sequitur, quod implicas contradictionem. $\quad \mathrm{R} 32 \mathrm{~m}$

...Ad magnum bonum faciendum dominas et Raimundum posuit in bonam spem. R32o

...plana veritate referta ad omnium utilitatem fidelium et Dei omnipotentis honorem R52

...theologus et maturus tamquam Phronesis decideret veritatem R66b

... Et tunc videbitur quis habebit veritatem. $\mathrm{R} 32 \mathrm{p}$

... et sic praescientia Dei non inducit necessitatem. R15

...non indigne feram me quencumque repperisse consortem. R23

... in ore duorum vel trium testium stabit omne verbum. $\mathrm{R} 14$

... quae earum triumphet, et ex hoc eligens quid sit agendum R75a

... ad aliquos principes, quibus sibi videbitur permittendum. $\mathrm{R} 32 \mathrm{x}$

...et aperiens mentis meae desiderium sic loquor [Hss. München: loquar] verbis meis ad eum. R8

... ad honorandum inter illos nostrum Dominum Deum. R32g

... quoniam corripiet me iustus in misericordia et increpabit me, oleum autem peccatoris non inpinguet caput meum [Ps 140, 5] R57b

...nullum rite fundatur exordium R5a, R5b, R5c

...Nunc enim credo Christum verum esse Deum et non alium R25

... in contrarium nimis est absurdum et temerarium. R17

... intellige dicta philosophorum et habebis totum magisterium.

... illa quae audiverunt et viderunt narrantium R52

...ne calumniose contra me moveret negotium $\mathrm{R} 22$

...non vult corrigere cum tamen hoc esset utilissimum. R17

... spiritum habeamus scripturarum. R39

...Intituletur autem iste liber contra Iudaeos quia firmiter agit contra eos seu appellatur Pharetra Iudaeorum R49

...per quem intratur in regnum coelorum $\mathrm{R} 13$

Te ergo deprecor ut me vivere facias et finire vitam ad gloriam tuam qui vivis et regnas cum Deo patre in unitate Spiritus Sancti, Deus per omnia saecula saeculorum. R36

... te regem gloriae dominumque virtutum in decore suo conspicientes, Iesum Christum, dominum nostrum, qui cum Patre et Spiritu Sancto vivit et regnat per omnia saecula saeculorum. R54 
...pro mercede quam nobis et vobis in vinea Domini laborantibus concedere dignaretur qui in trinitate personarum est unus Deus per infinita saecula saeculorum. $\quad$ R78

Ad quae inenarrabilia bona aeternae gloriae perducat nos Dominus noster Iesus Christus qui cum Patre et Spiritu Sancto vivit et regnat per infinita saecula saeculorum. R55

... sic ergo fuit Iesus Christus filius Dei passus, cui sit laus et gloria in saecula saeculorum. R59

... Si autem nihil talium, ut confido, immensas laudes summo refero Creatori, bonorum omnium largitori. Cui est laus et gloria in saecula saeculorum. R76

...plana veritate referta ad omnium utilitatem fidelium et Dei omnipotentis honorem. Cui sit gloria, laus et imperium in saecula saeculorum. R52

... Nunc enim credo Christum verum esse Deum et non alium, cui est honor et laus in saecula saeculorum. R25

...et puros coelestis aula suscipiet. Quam vobis concedat per meritum suae beatissimae passionis et per intercessionem suae sanctisimae matris Iesus Christus filius dei benedictus atque gloriosus in saecula saeculorum. $\mathrm{R} 61$

...et inhabitare digneris, iuxta sanctum et ineffabile tuum promissum, qui es benedictus in saecula saeculorum. R8

... totum renuens quod contristat, totum renuens quod delectat, qui semper es benedictus in saecula saeculorum. R57b

... a quo omnia sacramenta virtutem obtinent, dominum videlicet Fesum Christum, qui cum Patre et Spiritu Sancto vivit et regnat Deus benedictus in saecula saeculorum. R38

Iudaeus respondit ultimo: conducat nos per viam iustitiae ut veritatem valeamus percipere ab eo qui est benedictus in saecula saeculorum $\mathrm{R} 49$

...et aliis, quot saluti populi christiani utilius invenerit ordinare ad laudem Dei et gloriam Dei nostri Jesu, omnium salvatoris, qui est benedictus in saecula saeculorum. R57b

... spiritui tuo commemorasse sufficiat quod a facie Dei usque ad pedes ipsius Christo via duce pervenit. Et sic noster dialogus a Deo inceptus in Deo recte terminatus est, qui est benedictus in saecula saeculorum. R31

... demumque angelico misterio empireo perducitur sine fine mansura in gaudio coelo, cuius nos participes faciat trinus et unus deus qui sine fine vivit et regnat in saecula saeculorum $\mathrm{R} 67 \mathrm{a}$

...per quem intratur in regna coelorum, ad quae nos perducat, qui vivit et regnat in saecula saeculorum. R13

Iudaeus dicit: convertat nos Deus christianorum. $\quad \mathrm{R} 49$

... suam fidem esse meliorem quam fidem Iudaeorum et Christianorum. R32a

... Christus enim est panis vitae, de quo evangelium, satians quemlibet sensum beatorum. R66b

... sicut in tertia, quarta distinctione est ostensum. $\mathrm{R} 32 \mathrm{u}$

... Nihil est enim sine mensura ac partium proportione formosu. R56b

...et inhabitare digneris, iuxta sanctum et ineffabile tuum promissum R8

... ad se invicem intelligere et amare idem obiectum. $\mathrm{R} 32 \mathrm{u}$

...essentialiter et substantialiter nec non integraliter latitans et contentum $\mathrm{R} 65 \mathrm{~b}$

... ante articulos autem praemittunt prologum istum. R41

... cum magno tripudio prorumpens in iubilum decantare coepit: Iustus es, Domine, et rectum iudicium tuum. R19

... a quo omnia sacramenta virtutem obtinent, dominum videlicet Jesum Christum R38

... Incipe ergo sine mora primum tractatum. R52

...ille vos illuminet et auferat velamen de cordibus vestris, ut nobiscum valeatis videre rectum R11

... ut per hanc pertingamus ad eum qui est omnis desiderii finis et complementum. $\quad$ R27

Iudaeus dicit: convertat nos Christus [Variante: Deus]. Respondit christianus: Amen R49

Tunc dixit Cristianus. Amen R49

...tibi per ordinem explicabo. R21

Calicem salutaris accipiam et nomen Domini invocabo.

...correctionem caritativam nullatenus recusabo $\mathrm{R} 52$ 
...et aliis proficiendo ad praedicta leviter pervenire. Ecce similitudo. $\quad$ R24

... remansit caelestis militia cum gaudio. $\mathrm{R} 5 \mathrm{a}, \mathrm{R} 5 \mathrm{~b}, \mathrm{R} 5 \mathrm{c}$

... in mundis occupatio. R61

...Damone Pithiaque notis nominibus tractatur ipsa narratio. R71c

...si ipse cognoscit et diligit et honorat Deum ex propria libertate et sic non valet positio. R32e

... demumque angelico misterio empireo perducitur sine fine mansura in gaudio coelo R67a

... quod talem confabulationem habuerit cum diabolo. $\mathrm{R} 7 \mathrm{a}$

...et istud nomen 'infidelis' Iudaeo et Saraceno. R32w

... conquestionibus et quaestionibus quibus tuam adeo vexavi benignitatem hactenus finem pono $\mathrm{R} 73$

...et ne in conspectu tuo delinquam amplius in lingua mea, meo ori digitum superpono $\mathrm{R} 67 \mathrm{~b}$

... iam ergo implevi [Varianten: complevi, perfeci] intentionem meam in hoc libro. R39

...gratiam et gloriam apud Dominum obtinebis, gratiam in praesenti et gloriam in futuro. R55

... intelligantur in omnibus salva veritate, reverentia et honore sacrosanctae Romanae Ecclesiae, cuius correctioni haec et omnia alia mea dicta submitto. R32i

...perpetuo tibi silentium impono et a tua petitione vices rei agentem absolvo $\quad \mathrm{R} 2$

...ut maior vobis et iustior corrigendi quam mihi scribendi gloria debeatur. $\quad$ R64

... impius ima petens, quia pondus habere probatur/non abit ad caelum, sed ad infima praecipitatur. $\mathrm{R} 43$

...quod sanctorum doctorum prodit auctoritas et vivae rationis consonantia attestatur. $\quad \mathrm{R} 65 \mathrm{~b}$

... a sua poena non relevatur. $\mathrm{R} 5 \mathrm{C}$

...ex sua poena non relevatur. $\mathrm{R} 5 \mathrm{a}$

... ex ipsorum sententiis atque dictis quasi vice Rationis responsio subsequeretur. R34

...quod intellectus secundum suam naturam intelligendi suas proponat rationes et Fides secundum suam credendi reluctetur. $\mathrm{R} 32 \mathrm{k}$

...et ex corde compatiebantur. R21

... filio eius et ei compatiebantur. R21

...ut facilius a populo videantur et veritates eorum ut falsitates facilius cognoscantur. R66a

... hic inspicere poterunt christiani fideles ne per doctrinas erroneas inficiantur. R72

...et liberiori licentia tractantur. $\mathrm{R} 7 \mathrm{lb}$

... ut pervenire valeas unde expulsus es. $\mathrm{R} 48$

... quae ab ipsis pedibus et commesurationibus facile agnosces. R47a

...et compatiebantur ei omnes. $\mathrm{R} 21$

... et tuas probationes improbavi et tu non meas probationes. $\mathrm{R} 32 \mathrm{~s}$

... quis ipsorum deducit fortiores contra legem alterius rationes. R321

... refero per parabolas et metaphoras hos sermones. R32d

Codicis exigui stilus auctorem reticescens, /ingeror in medium, veluti nova verbula spargens. / Sic ut mitis amor terat aspera, mitius illa/corrigat, ac mores addat nota vera salubres. R16

...fatum esse aliquid iudicantes. $\mathrm{R} 47 \mathrm{~b}$

... datam tenere, nullatenus in hac trepidantes. R70

... Vos igitur reverendi patres opus accipite quod petistis, orationis si placet mercedem mihi pro labore pensantes. R57a

...te regem gloriae dominumque virtutum in decore suo conspicientes. R54

... sed iam orandum existimo ut Dei voluntas compleatur in nobis. R29

... eremita quaestiones proponendo ad gloriam et honorem, reverentiam, amorem, et recordationem et cognitionem Domini Dei nostri Jesu Christi et gloriosae virginis Mariae eius genitricis. R32f

... Prima operatio virtuosa est conversio hominis ad Deum et est prima distinctio huius libri et sic de aliis. R55

Littera: En pergo. Tu prosperum interim mihi iter, faustum deinde successum ac reditum superos ora. Vale. Anno imperii domini nostri Jesu Christi millesimo trecentesimo septuagesimo nono indictione secunda nonis ianuariis. R7la

... et Christus sic fuit eis inferior, licet sponte fuit passibilis et mortalis. R52 
... Et propter hoc ostenditur, quod doctrina data est valde utilis. $\mathrm{R} 32 \mathrm{v}$

... omniaque bona sua dispersit servitoribus bonis pauperibus ecclesiis monasteriis et sic bono fine discessit, quam nobis praestare dignetur filius Virginis R40

... in ordine perseverans bono fine quievit, plenus sanctitate et operibus bonis. $\quad \mathrm{R} 40$

... Obsecro genu flexo quod det vobis Deus spiritum consilii sanioris. R76

Reducat igitur eos misericors Deus ad paupertatis intelligentiam et amorem et dignetur caecitatis tam palpabiles effugare tenebras vitae suae operibus radiosis. $\mathrm{R} 41$

... sex distinctionibus in uno et sex in altero ordinatis. $\mathrm{R} 16$

... vestrum iudicium apponatis. R20

... sed potius vos valeatis protendere laudem Dei et procurare commoda totius christianitatis. R32e

... et quia pretiosissimum omnium est vita, et ideo dixit philosophus Aristoteles terribilissimum omnium est mors, etc. Declara sicut vis R63

...et eius exemplo et praecepto immo praeceptis, tam paroulos quam adultos esse baptizandos. R4

...Intituletur [Variante: intelligatur] autem iste liber contra Iudaeos quia firmiter agit contra eos $\mathrm{R} 49$

...Intitulatur iste liber contra Iudaeos quia agit contra eos $\quad$ R59

... Intituletur autem iste liber contra Iudaeos R49

...et angeli mali inducunt ad vitia ipsos malos. $\mathrm{R} 32 \mathrm{u}$

...quod beatus Petrus aliquando fuit usus sua auctoritate in alios apostolos. $\quad$ R52

...Deus cuius sola fruitio solius plena faciat nos esse beatos. R34

...pacem generalem Venetorum et Ianuensium et ad consolandum et visitandum Venetos. R32j

... Quod nobis praestare dignetur rex ille pacificus qui pia disposuit misera $<t>$ ione sibi subditos fore pudicos, pacificos et modestos. R68

... Christus in quantum homo veniet iudicare omnes vivos et mortuos. R32v'

Ratio. Age res tuas, curam hanc relinque viventibus. R56b

...Et abeuntes discesserunt ab invicem clericus et Raimundus. $\quad \mathrm{R} 32 \mathrm{t}$

Iudaeus dicit: convertat nos Deus R49

...quorum debitam solutionem exspectamus ad honorem illius, qui regnat Trinus et Unus Omnipotens Summus Deus. R32d

...et ad hoc, ut per totum mundum ametur et cognoscatur noster Dominus Deus. $\quad$ R32g

... ad honorem nati pueri Jesu Christi qui regnat cum Patre et sancto Spiritu, unus Deus. R32n

...de quodam libro quem compilavit contra Antichristum et adventum eius, ad laudem et servitium illius, qui est benedictus per omnia saecula verus Deus. R32c

... ille vos illuminet et auferat velamen de cordibus vestris, ut nobiscum valeatis videre rectum. Quod ipse praestare dignetur, qui cum patre et spiritu vivit et regnat Deus. R11

...et isti quinque libri erunt quinque lapides limpidissimi, quibus intereat cum Dei adiutorio Philisteus. R78

...de quodam libro quem compilavit contra Antichristum et adventum eius $\quad \mathrm{R} 32 \mathrm{c}$

...per hoc, quod credit unus, negat alius. $\mathrm{R} 32 \mathrm{w}$

... auctoritas legis antiquae sine reprehensione irrefragibilis auctoritatis illius $\quad$ R57a

...tempestas hortatur. Eamus R71b

...verumtamen in parte modum doctrinae artis demonstrativae, inventivae et amativae procedendo tenemus. R32f

...et tantum veritatem inquirendi desiderio, ut postea patuit, disputationem nostram exorsi sumus. R12

... quae visa sunt diximus, de altera quae dehinc visa fuerint dicemus. R56b

...cui similem non reor produxisse urbem prout fuit Africanus. $\mathrm{R} 69$

... mercurium crudum sed purgatum et super omne corpus. R51

...cum etiam de omni verbo otioso sit Dominus a nobis rationem exacturus. R17

... tam sublimis quam nobis praestare dignetur Christus in saecula saeculorum benedictus. $\quad$ R61

... asperrimam vitam duxit, ieiunando, vigilando, laborando, etiam debili medendo, ut nos ad aeterna gaudia revocaret, quae nobis concedat omnipotens Deus Pater et Filius et Spiritus Sanctus. $\mathrm{R} 1$

Iudaeus dicit: convertat nos Christus $\quad \mathrm{R} 49$ 
... sic ergo fuit Iesus Christus filius Dei passus R59

...ut in conspectu sublimis Dei fieret magis gratus. R32a

... ad quam consequendam pro viatico datum est nobis corpus Domini nostri Iesu Christi, qui cum Patre et Spiritu Sancto vivit et regnat in saeculorum saecula benedictus. R75a

...et sic scribendi dicendique et conferendi finem, luce illa, dulci cum sui recordatione largitus. $\mathrm{R} 42$

...prohemio finii contentus $\mathrm{R} 68$

... beata Maria [Variante: Virgo] ad singula respondebat. R21

... Raymundus et Eremita multum devote et humiliter inter se acceperunt commeatum et unus rogavit alium, quod pro se oraret nostrum Dominum Deum Fesum Christum et beatam Virginem matrem eius, in quorum custodia hunc librum commendat. R32i

...et ecclesiis bona sineat[?]. R40

... ad iudicium venit nullus est qui sciat. $\mathrm{R} 21$

... sileat mundus et fortuna non obstrepat. R56a

... totum renuens quod contristat, totum renuens quod delectat $\mathrm{R} 57 \mathrm{~b}$

... si hostibus suis, saltem prout possum, non resistat. R13

... Coniugii foedus oratione elegantissima sancit, una repatrient iubet. R71c

... tempus est etiam ut materia secundi voluminis inchoetur. Igitur incipe quando placet. $\quad \mathrm{R} 45$

... et puros coelestis aula suscipiet R61

... asperrimam vitam duxit, ieiunando, vigilando, laborando, etiam debili medendo, ut nos ad aeterna gaudia revocaret $\mathrm{R} 1$

...Qui ergo parce laudat, parcius vituperet. R9

... licet indigno assensum libens praebuit et sic exorsa ait. R35

... Huius verbi misterium sequens parabola declarabit. R26

...pro me fratrum praedicatorum minimo lacrimas reddit. R31

...beata Maria [Variante: Virgo] ad singula respondit. R21

... sicut novellae olivarum in circuitu mensae Domini saciabimur, apparente nobis gloria fructus ventris virginis benedictae, quod nobis ipse concedat, qui nos de nihilo creavit et suo sanguine pretioso redemit. $\mathrm{R} 77$

... spiritui tuo commemorasse sufficiat quod a facie Dei usque ad pedes ipsius Christo via duce pervenit R31

...et sic operi consummationem imponit. $\mathrm{R} 57 \mathrm{~b}$

...haec eadem omnibus Deum diligentibus communicari praecepit. $\quad$ R54

Ratio: O felix nisi te spes ista fefellerit. R56b

...Praedictis rationibus auditis a Saraceno, ipse diu consideravit et post suspiravit, et a christiano se distavit et disputationem ei dimisit. R321

...et sic in benedictione divina alter alterius recipiens comeatum, Canonista solus peregrinus recessit. $\mathrm{R} 79$

...et ab eo discessit. $\quad \mathrm{R} 40$

...omniaque bona sua dispersit servitoribus bonis pauperibus ecclesiis monasteriï et sic bono fine discessit R40

... et vos religiosi plus desistitis ab oratione defunctis quam solebatis, curatis ne pereatis et his dictis siluit. R46

... Quo audito recessit, et amplius ad conflictum venire noluit. $\mathrm{R} 33$

... et illos alios damnatos in aeternis miseriis et tenebris dereliquit. R3

... Quo circa divinarum humanarumque rerum notitia laudat efficaci ratione philosophum quam digesta per mores experientia comprobavit. $\mathrm{R} 47 \mathrm{c}$

... in muscipulam crucis exterminavit. $\mathrm{R} 2$

... in tali casu iudex allegationibus calumniose damnavit. R18

...et quae minus dixeram, alicubi supplevit. $\mathrm{R} 17$

...et sic in sancto ordine vitam suam feliciter finivit. $\quad \mathrm{R} 40$

... sed gratia disputationis illa dixit. $\mathrm{R} 32 \mathrm{k}$

... reprehendere quia fortunam maledixit. $\mathrm{R} 32 \mathrm{j}$ 
... Et ab ipsis responsionem bonam, humilem et devotam exspectaverunt. Ad gloriam et laudem Domini nostri Iesu Christi et benignissimae dominae nostrae matris eius, in cuius custodia ac beatorum angelorum hunc librum deponimus et commendamus.Et Deus Pater, Deus Filius et Deus Spiritus sanctus de hac commendatione in die iudicii testimonium faciant. $\mathrm{R} 32 \mathrm{~h}$

... in hoc enim praedicti quatuor sapientes in Libro Gentilis concorditer convenerant. $\quad \mathrm{R} 32 \mathrm{~b}$

... a quo omnia sacramenta virtutem obtinent $\mathrm{R} 38$

...cum effusione sanguinis pro viribus confutarunt. R78

... ita triginta Iudaeos pro denario vendiderunt. $\mathrm{R} 21$

... sed ipsi Christum emerunt. R21

... Et ita utraque pars cum gaudio et laetitia recesserunt. $\quad \mathrm{R} 24$

Et ab ipsis responsionem bonam, humilem et devotam exspectaverunt $\mathrm{R} 32 \mathrm{~h}$

... qui utique scripturas quas docuerunt alto ingenio intellexerunt. R74a

...Averroista et Raimundista finierunt istum librum, et ipsum venerandae facultati Parisius obtulerunt, ut ab ipsa daretur judicium super his, quae dixerunt. $\mathrm{R} 32 \mathrm{r}$

...Vae mihi quia tacui [Is 6, 5] et vae, Domine, tacentibus de te quoniam loquaces multi facti sunt R30

... his ille me primum verbis aggressus est. $\mathrm{R} 56 \mathrm{a}$

... spiritui tuo commemorasse sufficiat quod a facie Dei usque ad pedes ipsius Christo via duce pervenit. Et sic noster dialogus a Deo inceptus in Deo recte terminatus est. $\quad$ R31 


\section{Handschriften}

Die Handschriften sind nach Standort (in der gegenwärtigen Landessprache) und Bibliotheken sortiert. Eine Auflistung der Abkürzungen von Bibliotheksnamen findet sich auf S. xxv. Bei Verweis auf die Repertoriumsnummer sind die Handschriften in der Rubrik „Überlieferung“ zu finden. Ansonsten wird die jeweilige Rubrik (zum Teil in abgekürzter Form: Bearb $<$ eitungen $>$, Dat $<$ ierung $>$, Edit $<$ ionen $>$, Fass $<$ ungen $>$, Übers<setzungen>) angegeben.

Aachen, StB: 49

R16

Aberystwyth, National Library of Wales:

$\begin{array}{ll}\text { Peniarth } & 336 \mathrm{~A} \\ \text { (Hengwrt 220) } & \text { R56a }\end{array}$

Admont, StiftsB:

$\begin{array}{ll}405 & \text { R34 } \\ 492 & \text { R34 } \\ 550 & \text { R21 }\end{array}$

Alba Julia (Karlsburg), Bibl.

Batthyányana: cod. I 157

R21

Angers, BM: $258 \quad$ R73

Ansbach, Staatliche Bibliothek (Schlossbibliothek):

$\begin{array}{ll}\text { Ms. lat. 1 } & \text { R75a } \\ \text { Ms. lat. 22 } & \text { R75b } \\ \text { Ms. lat. 72 } & \text { R75a }\end{array}$

Arras, BM: 745 (784) R56a

Aschaffenburg, StiftsB:

$\begin{array}{ll}\text { Pap. 25 } & \text { R75b } \\ \text { Perg. 25 } & \text { R6, R21 }\end{array}$

Assisi, Biblioteca Comunale:

$\begin{array}{ll}138 & \text { A11 } \\ 691 & \text { R23 }\end{array}$

Assisi, Biblioteca storico-francescana della Chiesa Nuova: 380

R23

Auckland, Public Library:
G. 142
R56b

Augsburg, Staats- und StB:

$2^{\circ}$ Cod. 67 R75b

$2^{\circ}$ Cod. 197 R32f

$2^{\circ}$ Cod. $273 \quad$ R21 $\begin{array}{ll}4^{\circ} \text { Cod. } 24 & \text { R75a } \\ 8^{\circ} \text { Cod. } 127 & \text { R32k }\end{array}$

Augsburg, UB:

Cod. II.1.4 $50 \quad$ R56a

Cod. II.1.2 $2^{\circ} 31 \quad$ R40

Cod. II. $1.2^{\circ} 65 \quad$ R29

Avignon, Bibliothèque du Musée

Calvet:

$1100 \quad$ R61

Bad Gandersheim, StiftsB:

Hs. 261

R21

Bad Windsheim, StB:

84

R75a

98

R21

Bamberg, SB:

Class. 91 (M II 9) R56a

Theol. 113 (Q. III. 11) R61

Theol. 115 (Q. VI. 34) R61

Barcelona, Archivo de la Corona de Aragón:

Ripoll $167 \quad$ R46

Barcelona, Biblioteca Central: 682

R32k,

R32n,

R32o

Barcelona, Biblioteca de la

Universitat:

728

R321

Basel, UB:

$\begin{array}{ll}\text { A. IV. } 25 & \text { R61 } \\ \text { A. VIII. } 28 & \text { R61 } \\ \text { A. X. } 119 & \text { R61 } \\ \text { B. V. } 13 & \text { R61 } \\ \text { B. V. } 34 & \text { R61 } \\ \text { B. VII. } 29 & \text { A16 } \\ \text { E. I. } 11 & \text { R37 } \\ \text { F. V. } 27 & \text { R60 } \\ \text { O. I. } 8 & \text { R61 }\end{array}$



O. I. 10
O. II. 32
R56a
R60

Bayeux, Bibliothèque du Chapitre: 42

R59

Bergamo, Biblioteca Civica

Angelo Mai:

$\begin{array}{ll}\Delta 5.25 & \mathrm{R} 60 \\ \Lambda \text { II 32 } & \mathrm{R} 60 \\ \Sigma \text { II. 8 } & \mathrm{R} 60 \\ \begin{array}{l}\text { I I sopra 5/6 } \\ \text { (MA 504) }\end{array} & \mathrm{R} 47 \mathrm{c}\end{array}$

Berlin, SBB-PK:

Diez. C fol. 2

Hdschr. 328

Hamilton 502

lat. fol. 187

lat. fol. 628

lat. fol. 745

(Görres 42)

lat. fol. 862

lat. oct. 50

lat. qu. 30

lat. qu. 385

lat. qu. 814

mgo 467

Ms. Magdeb. 36

Ms. Magdeb. 47

theol. lat. 167

theol. lat. fol. 129

theol. lat. fol. 162

theol. lat. fol. 639

theol. lat. fol. 710

theol. lat. qu. 284

$\mathrm{R} 46$

R16

R60

R32a

R5b

R61

R5a

R11

R74a

R60

R61

R55 (Übers./

Bearb.)

R74b

R57b

R75a

R29

R61

R46

$\mathrm{R} 75 \mathrm{a}$

R60

Bernkastel-Kues, Bibliothek des St.

Nikolaus-Hospitals:

$\begin{array}{ll}42 & \text { R36 } \\ 64 & \text { R57a } \\ 83 & \text { R32j, R32o, } \\ & \text { R32q, R32r, } \\ & \text { R32t, R32u, } \\ & \text { R32x } \\ 84 & \text { R32i } \\ 86 & \text { R32d, R32g } \\ 104 & \text { R75b } \\ 200 & \text { R56a } \\ 201 & \text { R39 }\end{array}$

Besançon, BM: 139 Biberach, Spitalarchiv:
cod. B $3539 \quad$ R75a

Binghampton, Library of the State University of New York, Special

Collections: Vault Ms R56b

Bologna, Biblioteca Comunale del Archiginnasio:
A. 34
R5a

Bologna, BU:

$\begin{array}{ll}104 & \text { R39 } \\ 105 & \text { R39 } \\ 138 & \text { R58 } \\ 153 & \text { R39 } \\ 164 & \text { R58 } \\ 168 & \text { R51 } \\ 168 & \text { R58 } \\ 270 & \text { R51 } \\ 500 & \text { R39 } \\ 601 & \text { R58 } \\ 1732 & \text { R32a } \\ 2073 & \text { R47a }\end{array}$

Bologna, Collegio di Spagna:

$$
126 \quad \text { R5b }
$$

Bonn, UB:

$$
\text { S. } 1035 \quad \text { R60 }
$$

Bordeaux, BM:

$$
406 \quad \text { R37 }
$$

Bösensell (Münster), Archiv Haus Ruhr:

$$
73 \text { R56b }
$$

Bratislava, Kapitulská Knižnica: 49 R21

Braunschweig, StB:

$\begin{array}{ll}\text { ms. 70 } & \text { R53 } \\ \text { ms. 120 } & \text { R61 } \\ \text { ms. 127 } & \text { R61 } \\ \text { ms. 134 } & \text { R61 } \\ \text { ms. 158 } & \text { R53 }\end{array}$

Bremen, Staatliche Bibliothek: lat. b. $35 \quad$ R52 (Übers./ Bearb.) 
Brno (Brünn), Státní Vědecká

Knihovna:

Mk 43 (II 148) R26

Mk 46 (II 149) R34

R 357 (D/K.I.

alep. II)

R56a

Brugge, Bibliotheek van het

Grootseminarie:

113/78R56a

Brussel/Bruxelles, KBR:

$\begin{array}{ll}\text { II. 1159 } & \text { R44 } \\ 471 & \text { R57a } \\ 806 & \text { R61 } \\ 1138-59 & \text { R61 } \\ 1171-72 & \text { R55 (Übers./ } \\ & \text { Bearb.) } \\ 2620-34 & \text { R61 } \\ 5122-26 & \text { R61 } \\ 14486-14491 & \text { R56a } \\ 15156 & \text { R55 (Übers./ } \\ & \text { Bearb.) } \\ 15698 & \text { R56b } \\ 19410 & \text { R32o } \\ 20046-53 & \text { R62 } \\ 21950 & \text { R56a }\end{array}$

Budapest, Eötvös Loránd

Tudományegyetem Egyetemi Könyvtár:

$\begin{array}{ll}\text { lat. } 50 & \text { R14 } \\ \text { lat. } 54 & \text { R61 } \\ \text { lat. } 59 & \text { R74b }\end{array}$

Budapest, Magyar Nemzeti Múzeum: 277 R61

Budapest, Országos Széchényi

Könyvtár:

Clmae $488 \quad$ R56b

Burgo de Osma, Archivo Biblioteca de la Catedral: 35

A9

Cambrai, BM:

$920 \quad$ R51

Cambridge, Corpus Christi College:

$99 \quad$ R58

156 R37

$180 \quad$ R57b

382 R57b

392 R59

Cambridge, Peterhouse: 271

R56a
Cambridge, St. John's College:

$\begin{array}{ll}115 & \text { R37 } \\ 160 & \text { R37 }\end{array}$

Cambridge, Trinity College:
B. 1538
A18
O. 2.47
R39
R. 14.45
R39

Cambridge, UL:

Mm. 6. $12 \quad$ R36

Cambridge (Mass.), Harvard UL: Typ. $127 \mathrm{H} . \quad$ R64

Cesena, Biblioteca Malatestiana:

Pluteo dest. XIX $1 \quad$ R57a

Chambéry, BM:

$$
4 \quad \text { R23 }
$$

Chantilly, Musée Condé: 327 (642)

R39

Clermont-Ferrand, BM: 153

R14, R15

Collegeville (Minnesota), St. John's Abbey and University Hill Monastic Manuscript Library:
A 5
R21

Cortona, Biblioteca del Comune e dell'Academia Etrusca:

$$
132 \text { (213) R32o }
$$

Cremona, Biblioteca Statale (olim

Biblioteca Governativa): 143 R48

Częstochowa, Biblioteka Paulinów: Cod. II $27 \quad$ R6

Darmstadt, Hessische Landes- und Hochschulbibliothek:

$\begin{array}{ll}535 & \text { R5a } \\ 1980 & \text { A16 }\end{array}$

Den Haag siehe 's Gravenhage

Dessau, StB: BB $3944 \quad$ R75a

Dijon, BM: 235 (196) R57b

Dillingen, Studienbibliothek: XV $29 \quad$ R3

Dôle, BM: 109

R14 
Douai, BM:

$\begin{array}{ll}269 & \text { R56a } \\ 397 & \text { R16 }\end{array}$

Dresden, Sächsische LB:

$\begin{array}{ll}\text { F 61 } & \text { R21 } \\ \text { Schneeberger } & \\ \text { App. 2303 } & \text { R21 } \\ \text { Dublin, TCL: } & \\ \text { 189 } & \text { R57a } \\ \text { 190 } & \text { R57a, R57b } \\ 268 & \text { R15 } \\ \text { C. 5. } 6 & \text { R66a (Übers.) } \\ \text { C. 5. } 19 & \text { R14 }\end{array}$

Durham, UL:

Cosin V. III. 17 R44

Düsseldorf, ULB:

$\begin{array}{lll}\text { B } 185 & \text { R21 } & \\ \text { C } 27 & \text { C 26 } & \text { R16 } \\ \text { R16 } & \end{array}$

Eichstätt, UB:
Cod. st 112
Cod. st 321
R75a
Cod. st 417
R70
Cod. st 452
$\mathrm{R} 5 \mathrm{~b}$
Cod. st 529
R56a
R60

Einsiedeln, StiftsB:

$\begin{array}{ll}307 & \text { R56a } \\ 308 & \text { R60 }\end{array}$

Erfurt, Domarchiv: ms. theol. 14 R61

Erfurt, UB, Dep. Erf.:

$\begin{array}{ll}\text { CA } 2^{\circ} 5 & \text { R56a } \\ \text { CA } 4^{\circ} 82 & \text { R26 } \\ \text { CA } 4^{\circ} 116 & \text { R26 } \\ \text { CA } 4^{\circ} 118 & \text { R5a } \\ \text { CA } 4^{\circ} 145 & \text { R70 } \\ \text { CA } 4^{\circ} 312 & \text { A11 } \\ \text { CA } 4^{\circ} 388 & \text { R3 } \\ \text { CA } 8^{\circ} 51 & \text { R6 }\end{array}$

Erlangen, UB:

$\begin{array}{ll}499 & \text { R34 } \\ 575 & \text { R6 } \\ 576 & \text { R61 } \\ 589 & \text { R29 } \\ 644 & \text { R56a }\end{array}$

Escorial, Real Biblioteca de San Lorenzo:
2. G. 6
R79
\&. IV. 6
R32i
d. II. 12
R5B
r. II. 14
R43
v. III. 9
R61

Eton, College Library:

$\begin{array}{ll}47 & \text { R65b } \\ 130 & \text { R12 }\end{array}$

Firenze, BML:

Aedilium $37 \quad$ R4

Ashburnham 1099 R56a

Ashburnham 1550 R48

Laur. 89 sup. $16 \quad$ R60

Plut. XIX. $33 \quad$ R66

Plut. XXVI sin. $9 \quad$ R56a

Plut. LXXVIII 2 R56a

Plut. LXXVIII 5 R56a

Plut. LXXXIX

inf. $35 \quad$ R56a

Strozzi $90 \quad$ R56b (Edit.)

Strozzi $91 \quad$ R56a

Firenze, BNC:

II. I. $64 \quad$ R71c

II. III. $25 \quad$ R51

Landau Finaly 253 R56a

Acquisti e Doni 227 R60

Conv. sopp. D.

$7.1831 \quad$ R45

Conv. sopp. E.

6. 1046 A21

Conv. sopp. G.

$\begin{array}{ll}\text { 3. 368 } & \text { R36 (Übers.) } \\ \text { Pal. Capponi 31 } & \text { R56b (Übers./ } \\ & \text { Bearb.) }\end{array}$

Firenze, Biblioteca Riccardiana:

$\begin{array}{ll}923 & \text { R39 } \\ 1164 \text { (L. III. 32) } & \text { R51 } \\ \text { L.III.xxvii } & \text { R39 } \\ \text { persc. (Kat. Lami, } & \\ \text { 302, 365) } & \text { R5 }\end{array}$

Frankfurt a. M., StUB:

lat. qu. 4

Ms. Barth. 72

R52 (Autor)

Ms. Barth. $99 \quad$ R21

Ms. Barth. $138 \quad$ R61

Ms. Barth. $140 \quad$ R61, R75a

Ms. Barth. 163 R49

Ms. Barth. $164 \quad$ R21

Ms. Praed. 33 R6

Ms. Praed. $58 \quad$ R36

Ms. Praed. $59 \quad$ R5a

Ms. Praed. $61 \quad$ R5a 
Ms. Praed. 74

Ms. Praed. 125

R6

$\mathrm{R} 5 \mathrm{~b}$

Freiburg im Breisgau, UB:

117

456

Fritzlar, Dombibliothek:

ms. 22

ms. 47

Fulda, Hessische LB:

$4^{\circ} \mathrm{C} 10$

Gdańsk (Danzig), Biblioteka Gdańska

PAN:

$\begin{array}{ll}1947 & \text { R56a } \\ 1958 & \text { R61 } \\ 1959 & \text { R67b, } \\ & \text { R75b } \\ \text { 1961 } & \text { R61 } \\ \text { 1980 } & \text { R61 } \\ \text { Mar. F 135 } & \text { R61 } \\ \text { Mar. O 20 } & \text { R74b } \\ \text { Mar. Q 13 } & \text { R61 } \\ \text { Mar. Q 22 } & \text { R61 } \\ \text { Mar. Q 35 } & \text { R61 }\end{array}$

Genève, Bibliothèque publique et universitaire:

lat. 86

R60

Gent, Centrale Bibliotheek,

Rijksuniversiteit te Gent: 1305

R55

(Übers./

Bearb.)

Gießen, UB:

691

R21

731

R53

733

R37

771

R75b

803

R38

809

R61

Girona, Biblioteca Capitular: ms. 930

R56b

Glasgow, UL:

Hunter 480 (V. 7. 7) R56a

Görlitz, Milich'sche Bibliothek:

Cod. chart. $2^{\circ} 30$

R61

Cod. chart. $2^{\circ} 46$

R61

Cod. chart. $2^{\circ}$ (B.A.) $30 \quad$ R61

Cod. chart. $2^{\circ}$ (B.A.) $80 \quad$ R61
Göttingen, Niedersächsische SUB:

Luneb. 32 R61

Gravenhage siehe 's

Gravenhage

Graz, UB:

$117 \quad$ R22

159 R21

312 R26

655 R59

$851 \quad$ R59

873 R26

1226 R36

1617 R34

Halle an der Saale, ULB

Sachsen-Anhalt:

Qu. Cod. $104 \quad$ R49, R59

Qu. Cod. $207 \quad$ R21

Stolb.-Wern. Za $72 \quad$ R56a

$\mathrm{Yg} 4^{\circ} 5 \quad \mathrm{R} 5$

Hamburg, SUB:

theol. 1048a $\quad$ R46

theol. 1057 R61

theol. $1534 \quad$ R49, R59

theol. $1660 \quad$ R5a

theol. $2219 \quad \mathrm{R} 16$

Heiligenkreuz, StiftsB:

107 R21

$290 \quad$ R70

Herzogenburg, StiftsB:

$329 \quad$ R75a

Hildesheim, Dombibliothek: 726

R21

Hildesheim, StB:

Andreanum 2 R56b

Innsbruck, UB:

$36 \quad \mathrm{R} 17$

$129 \quad \mathrm{R} 70$

$234 \quad$ R60

Ithaca (NY), Cornell UL, Rare Books: Mss Bd. Petrarch

P P49 S4+ R56a

Kaliningrad (Königsberg), Staats- und Universitätsbibliothek:
153 fol.
R56b
1240
$\mathrm{R} 75 \mathrm{~b}$ 
Karlsruhe, Badische LB:

Aug. 10

K 350

R61

R29

Kassel, LB und Murhardsche Bibliothek der Stadt:

$\begin{array}{ll}2^{\circ} \text { Ms. iurid. } 58 & \text { R19 } \\ 2^{\circ} \text { Ms. theol. 105 } & \text { R46 } \\ 8^{\circ} \text { Ms. theol. 10 } & \text { R61 }\end{array}$

Kiel, UB:

ms. Bord. 32

ms. Bord. 52

R61

R61

Klosterneuburg, StiftsB:

$\begin{array}{ll}428 & \text { R34 } \\ 637 \mathrm{~B} & \text { R5b } \\ 700 & \text { R70 } \\ 933 & \text { R26 } \\ 934 & \text { R34 } \\ 1067 & \text { R9 }\end{array}$

København, Det Kongelige Bibliotek:

Gl. kongel. Saml.

1370 qu.

R61

Gl. kongel. Saml.

3308 oct.

$\mathrm{R} 75 \mathrm{a}$

Gl. kongel. Saml.

3478 oct.

R32i, R32v

Koblenz, Landeshauptarchiv:

Best. 701 Nr. 150 R16

Best. 701 Nr. 152 R16

Best. 701 Nr. $164 \quad$ R38, R75a

Best. 701 Nr. 169

$\mathrm{R} 75 \mathrm{a}$

Köln, HAStK:

2025

R16 (Übers./

Bearb.)

GB fol. 74

R32b

GB fol. 87

GB oct. 8

R16

R75a

GB oct. 40

GB oct. 54

R75a

$\mathrm{R} 46$

GB oct. 60

GB oct. 87

R75a

R17

GB qu. 21

R5a

R21, R59

GB qu. 214

R17

W 33

R61

Kórnik, Biblioteka Kórnick: PAN, 1383

R59

Košice, Biskupska Knižnica:

Dd IV 54

$\mathrm{R} 75 \mathrm{~b}$
Kraków (Krakau), Biblioteka

Jagiellońska:

$\begin{array}{ll}321 & \text { R21 } \\ 325 & \text { R75b } \\ 554 & \text { R61 } \\ 1599 & \text { R57a } \\ 1623 & \text { R75b } \\ 2186 & \text { R75b } \\ 2220 & \text { R75a } \\ 2294 & \text { R75b } \\ 2549 & \text { R61 } \\ 2614 & \text { R75a }\end{array}$

Kremnica (Kremnitz), Farská Knižnica: Cx III (Sopko 164) R40

Křivoklát (Pürglitz), Křivoklátská

Knihovna:

1 d. 39 (Bibliothek

des Fürsten Max

Egon von

Fürstenberg, 126) R56b

Leiden, BR:

Ablaing $29 \quad$ R5b

Voss. chym. Q. $25 \quad$ R51

Leipzig, UB:

$487 \quad$ R75a

$595 \quad$ R75a

911 R22

916 R5a

$1091 \quad$ R74b

1259 R56b

$1260 \quad$ R56a, R56b

Haen. $15 \quad$ R5c

Leuven, Katholieke Universiteit,

Bibliotheek der Fakulteit

Godgeleerdheid:

Fonds Seminarie Mechelen, 47

R56b

Lilienfeld, StiftsB:

67

R21

Linköping, Stifts- och Landesbiblioteket: cod. BR I R5a

Linz, Bundesstaatliche Studienbibliothek: Ink. 48 (299) R56a

Lisboa, Arquivo Nacional da Torre do Tombo: 447 
Lisboa, Biblioteca Nacional: Fundo Alcobacense, cod. 71

London, BL:

Add. 16431

Arundel 138

Cotton Nero D. VIII, 10

Cotton Vespasianus A. VI

Cotton Vespasianus E. I

Harley 106

Harley 635

Harley 912

Harley 2541

Harley 2542

Harley 3454

Harley 3528

Harley 6348

Lansdowne 397

Royal 6. D. X

Royal 6. E. III

Royal 8. A. XIII

Royal 8. F. XI

Royal 10. B. IX

Sloane 441

Sloane 692

Sloane 1118

Sloane 2327

Stowe 1070

London, Lambeth Palace:

$$
121
$$

158

London, Wellcome Institute: 383

384

441

513

Lübeck, Bibliothek der Hansestadt

Lübeck:

Cod. theol. lat. 64

R3

Lucca, Biblioteca Capitolare Feliniana: N. 101

N. 510

R5

R5

Lucca, Biblioteca Governativa: 2128

R60

Lüneburg, Ratsbücherei:

Theol. $2^{\circ} 71$

R29
Lyon, BM:

$168(100) \quad$ R60

fonds général $258 \quad$ R79

(Übers./

Bearb.) Madrid, Biblioteca Histórica de la

Universidad Complutense:

$\begin{array}{ll}\text { BH MSS 64 } & \text { R32i } \\ \text { BH MSS 65 } & \text { R32n, R32o } \\ \text { BH MSS 129 } & \text { R60 }\end{array}$

Madrid, BN:

$54 \quad$ R56a

1474 A3

3353 R32o (Übers.)

Mainz, Bibliothek des Bischöflichen

Priesterseminars:

$\begin{array}{ll}34 & \text { R6 } \\ 220 \mathrm{~b} & \text { R32s, R32w } \\ 280 & \text { R56a }\end{array}$

R56a $280 \quad$ R56a

R2 Mainz, StB:

R65a, I 13 R32k

R65b I $16 \quad$ R75b

R37 I 33 R75a

$\begin{array}{lll}\text { R56a } & \text { I } 103 & \text { R21 }\end{array}$

R26 I $107 \quad$ R57a

$\begin{array}{lll}\text { R60 I } 130 & \text { R26 }\end{array}$

$\begin{array}{lll}\text { R18 I } 132 & \text { A16 }\end{array}$

$\begin{array}{lll}\text { R39, } & \text { I } 136 & \text { R21 }\end{array}$

R58 I $144 \quad$ R21

R39 I $150 \quad$ R75a, R75b

I 151 R5a

I $164 \quad$ R21, R75a

I $174 \quad$ R61, R75a, A16

I $175 \quad$ R75a

I $245 \quad \mathrm{R} 1$

I 249 R21

I 471 a $\quad$ R59

II $223 \quad$ R70

II $234 \quad$ R32a

Manchester, John Rylands UL:

eng. $86 \quad$ R66a (Edit.)

lat. $65 \quad$ R39

lat. $178 \quad \mathrm{R} 60$

Marburg, UB:

ms. 60 (D 23) R74b

Marseille, BM:

$211 \quad$ R5a

Melk, StiftsB:

778 R56a

896 R56a 


$\begin{array}{ll}\begin{array}{ll}\text { Metz, BM: } \\ 155\end{array} & \text { R61 } \\ 484 & \text { R38 } \\ \text { Milano, BA: } & \\ \text { A. } 5 \text { sup. } & \text { R32g } \\ \text { C. } 145 \text { inf. cart. misc. } & \text { R60 } \\ \text { D. } 223 \text { inf. misc. } & \text { R60 } \\ \text { D. } 369 \text { inf. } & \text { R79 } \\ \text { I. } 64 \text { inf. } & \text { R48 } \\ \text { I. } 98 \text { sup. } & \text { R56a } \\ \text { J. } 33 \text { inf. misc. } & \text { R60 } \\ \text { J. 246 inf. misc. } & \text { R60 } \\ \text { N. 259 sup. } & \text { R32w, R32x } \\ \text { P. } 79 \text { sup. } & \text { R32c } \\ \text { P. 198 sup. } & \text { R32d } \\ \text { S. 27 sup. } & \text { R13 (Edit.) } \\ \text { Y. 131 } & \text { R60 } \\ \text { fondo Trotti } 356 \text { misc. } & \text { R60 } \\ \text { sussidio H 52 } & \text { R60 }\end{array}$

Milano, Biblioteca Nazionale Braidense (Brera):

$\begin{array}{ll}\text { AB XI } 23 & \text { R60 } \\ \text { AD IX } 36 & \text { Ala }\end{array}$

Milano, Biblioteca Trivulziana: 751

R60

Milano, Sant'Eustorgio: Nr. 534

R35

Milano, Società Storica Lombarda: $43 \quad$ R71a

Modena, Biblioteca Capitolare: O. I. 15 R71b

Modena, Biblioteca Estense: Fondo Estense, 16

$$
\text { (Alpha P 9, 10) R56a }
$$

Modena, Raccolta Molza-Viti

(Principessa Beatrice Rospigliosi): cod. 17

R56a

Montpellier, Bibliothèque de la Faculté de Médecine:

$$
485 \text { R51 }
$$

Montserrat, Biblioteca del Monasterio: $341 \quad$ R32o

Mühlhausen Thomas-Müntzer-Stadt,

Kreisarchiv: $132(\operatorname{olim} 60 / 10) \quad$ R56b

München, BSB:

Cgm 660

R5a
Cgm $661 \quad$ R53

Cgm $686 \quad$ R61

Cgm 2928 R57b

Cgm 5235 R21

Clm $78 \quad$ R60

Clm $249 \quad$ R28

Clm $350 \quad$ R56a

Clm $361 \quad$ R60

Clm $426 \quad$ R60

Clm $455 \quad$ R58

Clm $499 \quad$ R75b

Clm $504 \quad$ R60

Clm $518 \quad$ R56a

Clm $1222 \quad$ R48

Clm $3243 \quad$ R26

Clm $3331 \quad$ R5b

Clm 3334 R5a

Clm $3547 \quad$ R61

Clm $3554 \quad$ R62

Clm $3588 \quad$ R59

Clm $3603 \quad$ R34

Clm $3762 \quad$ R49

Clm $4365 \quad$ R61

Clm $4687 \quad$ R74b

Clm $4789 \quad$ R59

Clm $5304 \quad$ R56a

Clm $5354 \quad$ R56a

Clm 5829 R60

Clm $5940 \quad$ R59

Clm $6499 \quad$ R61

Clm $7335 \quad$ R56a

Clm $7567 \quad$ R74b

Clm 7575 R8

Clm $7557 \quad$ R61

Clm $7714 \quad$ R61

Clm $7723 \quad$ R17

Clm 7785 A 19

Clm $7828 \quad$ R40

Clm 8448 R56b

Clm $8884 \quad$ R40

Clm $8969 \quad$ R61

Clm $8995 \quad$ R61

Clm $10495 \quad$ R32u

Clm 10497 R32a, R32b, R32g,

R32k, R32l

Clm $10505 \quad$ R32g

Clm 10512 R32d

Clm 10517 R32w

Clm $10519 \quad$ R32f

Clm $10525 \quad$ R32d

Clm 10532 R32i, R321

Clm 10533 R32e, R32g

Clm 10537 R32p, R32s

Clm $10541 \quad$ R32i 
Clm 10563

Clm 10564

Clm 10567

Clm 10571

Clm 10575

Clm 10576

Clm 10579

Clm 10580

Clm 10581

Clm 10584

Clm 10588

Clm 10589

Clm 10591

Clm 10593

Clm 10594

Clm 10595

Clm 10597

Clm 11478

Clm 11925

Clm 12395

Clm 14094

Clm 14134

Clm 14185

Clm 14232

Clm 14347

Clm 14553

Clm 14831

Clm 14243

Clm 15181

Clm 15228

Clm 16469

Clm 17796

Clm 18170

Clm 18413

Clm 18445

Clm 18551

Clm 18555b

Clm 18595

Clm 18621

Clm 18638

Clm 18757

Clm 18937

Clm 19610

Clm 19820

Clm 21059

Clm 23786

Clm 24801

Clm 26059

Clm 26608

Clm 27421

Clm 28394

Clm 28465

R32e
R32a, R32e, R32s
R321
R32i
R32a
R32e
R32i
R32e
R321
R32e
R32m, R32p, R32q,
R32s
R32r
R32g
R321
R32a, R32b, R32e,
R32k
R32d
R32o
R74a
R61
R8
R21
R60
R56a
R61
R74a
R59
R5a
R74b
R17, R40
R61
R40
R17
R56a
R61
R32g
R61
R60
R17
R40
R74b
R59
R75b
R26
R32g
R37
R49
R56a, R60
R51
R5a
R61
R21

$\begin{array}{ll}\text { Clm 28493 } & \text { R75a } \\ \text { Clm 28569 } & \text { R61 } \\ \text { Clm 28845 } & \text { R63 } \\ \text { Clm 28885 } & \text { R61 } \\ \text { Clm 28893 } & \text { R32g } \\ \text { München, UB: } & \\ 2^{\circ} \text { 301 } & \text { R5b } \\ \text { 4 799 }^{\circ} & \text { R56a } \\ \text { Münster, ULB; } & \\ \text { 319 } & \text { R61 }\end{array}$

Namur, Musée archéologique de la province de Namur, Fonds de la Ville: 52 R16

Napoli, BN:

$\begin{array}{ll}\text { VII. A. 34 } & \text { R53 } \\ \text { VIII. D. 20 } & \text { R39, R58 } \\ \text { I. H. 38 } & \text { R59 }\end{array}$

New Haven (Conn.), Yale University, Beinecke Rare Book and Manuscript Library: ms. 653 R19 (Übers./

Bearb.) ms. $992 \quad$ R7

ms. a 17

(Osborn Shelves) R60 Mellon ms. $5 \quad$ R39 ms. Marston 80 R56b

New York, Franciscan Institute Library, St. Bonaventure Univ.: ms. 4

$\mathrm{R} 32 \mathrm{e}$

New York, Library of the Hispanic Society of America:
B 1326
R21

Nürnberg, StB:

Cent. I. 53 R75b

Cent. III. $50 \quad$ R61

Cent. III. $69 \quad$ R61

Cent. IV. 77 R8

Cent. V. $68 \quad$ R33

Cent. VI. 46f. R55 (Übers./

Bearb.

Cent. VII. 64 R55 (Ubers./

Bearb.)

Olomouc (Olmütz), Státní archiv v

Opavě (fond Kapitulní Knihovna): Kapit. $63 \quad$ R74b 
Osek, Klášterní Knihovna: 20

R75a

Osnabrück, Bischöfliches Archiv: Hs. Frenswegen 4 R46

Hs. Frenswegen 21 R16 Hs. Ma 9

R46

Ottobeuren, StiftsB: O 22 (II 353) R74b

Oxford, Balliol College: 127

R56a 288

R71b, R71c, R71d

Oxford, BodL:

Arch. Seld. B. 25

Ashmole 1384

R32a

Ashmole 1398

R39

Ashmole 1450

$\mathrm{R} 2$

Auct. F. infra 1.2.

R39

Bodley 52

R57b

Bodley 158

$\mathrm{R} 2$

Bodley 339

R72

Bodley 881

$\mathrm{R} 64$

Canon. misc. 298

R61

Canon. misc. 370

R321

Digby 164

R36

e Musaeo 63

R39

R39

e Musaeo 86

R66

Laud. lat. 46

R32i

Laud. misc. 190

R21

Laud. misc. 298

R61

Laud. misc. 503

R56a

Laud. misc. 731

R64

Rawlinson G. 40

R37

Selden supra 41

R62

Oxford, Corpus Christi College:
D. 88 (F. 2. 12 .
R56a

Oxford, Lincoln College: lat. 18

R57a

Oxford, Merton College: 89 113

R32i, R32k

$\mathrm{R} 57 \mathrm{~b}$

Oxford, New College:

$\begin{array}{ll}90 & \text { R57a } \\ 155 & \text { R7 la } \\ 294 & \text { R39 }\end{array}$

Oxford, Pembroke College: 5

R57a

Oxford, Queen's College: 78. d. $4^{\circ}$

R56b

Paderborn, Erzbischöfliche

Akademiebibliothek:

Theodoriana Ba 11, fol. XXIr

Padova, Biblioteca Antoniana: 93

R61

Padova, Biblioteca Capitolare:
A. 60
$\mathrm{R} 41$
B. 38
$\mathrm{R} 32 \mathrm{~g}$

Padova, Biblioteca Civica:

$\begin{array}{lc}\text { B } 2531 & \text { R47b, R47c } \\ \text { BP } 1223 & \text { R60 }\end{array}$

Padova, BU:

MS 541

R60

Palermo, Biblioteca della Società Siciliana per la Storia Patria:
I. B. 25
R20

Palma de Mallorca, Archivo de la Curia: Causa Pía Luliana 2 R79

(Übers./

Bearb.)

Causa Pía Luliana $5 \quad$ R32p

Causa Pía Luliana 11 R32k, R32r,

Causa Pía Luliana38 R32i

Palma de Mallorca, Biblioteca

Bartolomé March Servera: cod. 102-V3-3

R321

Palma de Mallorca, Biblioteca Pública,:

\begin{tabular}{ll}
463 & R32l \\
1003 & R32k \\
1008 & R32k, R32n, \\
& R32p, R32s \\
1038 & R32f \\
1042 & R32v \\
1062 & R32a \\
1064 & R32t \\
1066 & R32i \\
1080 & R32r \\
1091 & R32g \\
Incunable 463, Int. II & R79 \\
Palma de Mallorca, Convento de los \\
manciscanos: \\
m-44 \\
\multicolumn{2}{l}{ R32r }
\end{tabular}




\begin{tabular}{|c|c|}
\hline Paris, Bibliothè & de l'Arsenal: \\
\hline 760 & R61 \\
\hline 2890 & $\mathrm{R} 46$ \\
\hline 8212 & R55 (Übers./Bearb.) \\
\hline Paris, Bibliothèq & de l'Institut de \\
\hline France: & \\
\hline Institut 615 & R56a \\
\hline Paris, BnF: & \\
\hline Coll. Doat 36 & R14 \\
\hline fr. 19965 & R32o (Übers.) \\
\hline lat. 1010 & R61 \\
\hline lat. 1093 & R5, R5a (Autor, Dat.) \\
\hline lat. 1462 & R70 \\
\hline lat. 1464 & R76 \\
\hline lat. 1466 & R78 \\
\hline lat. 1469 & R68, R69 \\
\hline lat. 1472 & R68 \\
\hline lat. 3088 & $\mathrm{R} 75 \mathrm{a}$ \\
\hline lat. 3174 & $\mathrm{R} 32 \mathrm{f}$ \\
\hline lat. $3180 \mathrm{G}$ & $\mathrm{R} 64$ \\
\hline lat. 3222 & $\mathrm{R} 57 \mathrm{~b}$ \\
\hline lat. 3323 & $\mathrm{R} 32 \mathrm{n}$ \\
\hline lat. 3353 & R59 \\
\hline lat. $3459 \mathrm{~A}$ & $\mathrm{R} 64$ \\
\hline lat. 3646 & R59 \\
\hline lat. 4364 & R37 \\
\hline lat. $6492 \mathrm{~A}$ & $\mathrm{R} 46$ \\
\hline lat. 6494 & R7le \\
\hline lat. 6502 & $\mathrm{R} 56 \mathrm{a}$ \\
\hline lat. 6728 & R56a \\
\hline lat. $6749 \mathrm{~B}$ & R39 \\
\hline lat. 7173 & R51, R58 \\
\hline lat. 7162 & R39 \\
\hline lat. 8507 & $\mathrm{R} 48$ \\
\hline lat. 8512 & R48 \\
\hline lat. 8582 & R60 \\
\hline lat. 10210 & R73 \\
\hline lat. 10770 & R5 \\
\hline lat. 11185 & $\mathrm{R} 32 \mathrm{i}$ \\
\hline lat. 12438 & $\mathrm{R} 57 \mathrm{a}$ \\
\hline lat. 12464 & $\mathrm{R} 37$ \\
\hline lat. 13605 & $\mathrm{R} 61$ \\
\hline lat. 14005 & R51 \\
\hline lat. 14177 & $\mathrm{R} 60$ \\
\hline lat. 14578 & $\mathrm{R} 57 \mathrm{a}$ \\
\hline lat. 14644 & R70 \\
\hline lat. 14713 & R321 \\
\hline lat. 15004 & R37 \\
\hline lat. 15096 & R321 \\
\hline lat. 15097 & $\mathrm{R} 32 \mathrm{n}$ \\
\hline lat. 15145 & $\mathrm{R} 32 \mathrm{j}$ \\
\hline lat. 15373 & $\mathrm{R} 57 \mathrm{~b}$ \\
\hline
\end{tabular}

lat. 15450

lat. 15974

lat. 16111

lat. 16112

lat. 16113

lat. 16114

lat. 16116

lat. 16117

lat. 16120

lat. 16558

lat. 17165

lat. 17827

lat. 17829

lat. 18111

$\begin{array}{ll} & \text { lat. 18216 } \\ & \text { R5a } \\ \text { nouv. acq. lat. 1274 } & \text { R10 } \\ \text { nouv. acq. lat. 1821 } & \text { R56a }\end{array}$

Paris, Bibliothèque Mazarine:

$\begin{array}{ll}895(440) & \text { R57a } \\ 896(1174) & \text { R57a } \\ 3051 & \text { R32t } \\ 3501 & \text { R32a } \\ 3506 & \text { R32a } \\ 3509 & \text { R321 } \\ 3522 & \text { R64 } \\ 3884(608) & \text { R60 }\end{array}$

Paris, Bibliothèque de la Sorbonne: 225

R57a

Pavia, BU:

Aldini 120

R79

Pelplin, Biblioteka Seminarium

Duchownego:

$\begin{array}{ll}70(107) & \text { R56a, R56b } \\ 182(220) & \text { R61, R75a } \\ & \text { (Edit.), R75b }\end{array}$

Perugia, Biblioteca Comunale Augusta: Fondo Nuovo 2862 R60 Fondo Vecchio J 25 R60 Fondo Vecchio J 134 R60

Philadelphia, Philadelphia Free Library:

Lewis European Manuscripts T 189 R56b

Philadelphia, Temple University: Cochran $501 \quad$ R37 
Pisa, Biblioteca Caterina: 54

$\mathrm{R} 48$

Pommersfelden, Gräfl. Schönbornsche Bibliothek: 257/2901

R6

Poznań (Posen), Archiwum

Archidiecezjalne: cod. 57

R56b

Praha, KMK:

$\begin{array}{ll}\text { A } 86 & \text { R74b } \\ \text { A 113.I } & \text { R40 } \\ \text { D 27 } & \text { R61 } \\ \text { D 60 } & \text { R56a } \\ \text { D 86 } & \text { R56b } \\ \text { G 12 } & \text { R74a } \\ \text { J 30 } & \text { R37 } \\ \text { N 37 } & \text { R15 } \\ \text { O 24 } & \text { R34 } \\ \text { O 29 } & \text { R66 } \\ \text { O 32 } & \text { R75b }\end{array}$

Praha, NK:

adlig. 44 D 2

A17

B. 15.38

A13

I. D. 5

R34

I. E. 37

A17

I. F. 5

R59

III. G. 18

V. B. 15

R60

R16

V. B. 21

VI. A. 5

$\mathrm{R} 74 \mathrm{~b}$

VIII. F. 131

R5b

IX. C. 3

IX. E. 9

R37

X. B. 7

R67b, R75b

R58

XI. C. 8

R59

R40, R61

XI. E. 2

$\mathrm{R} 40$

R66

XI. E. 3

XI. F. 7

R6

XII. D. 16.

$\mathrm{R} 75 \mathrm{~b}$

XIII. D. 21

R55 (Autor)

XIII. G. 3

R40

R21

XIII.H.3.h

R40

Reims, BM:

500

R32c

Reun, StiftsB: 58

R16

Roma, Biblioteca Casanatense:

159 (A. III. 14) R26

1022 (D. III. 17) R79 $\begin{array}{ll}1414 \text { (D. I. 5) } & \text { R32a, R32d } \\ 1533 \text { (O. V. 64) } & \text { R32o } \\ 1878 \text { (C. III. 4) } & \text { R45 }\end{array}$

Roma, Biblioteca Corsiniana

(Accademia dei Lincei):

Fondo Niccolò Rossi

78 (36 F 16)

R56a

Fondo Niccolò

Rossi 204 (43 E 13) R60

Fondo Niccolò Rossi

229 (33 E 27) R42

Roma, BNC Vittorio Emanuele II:

Fondo Vittorio

Emanuele $144 \quad$ R32s

Fondo Vittorio

Emanuel $244 \quad$ R32m, R32n,

R32o, R32p,

R32q, R32r

Fondi minori 1832 R32s

Roma, Collegio di Sant'Isidoro:

$\begin{array}{ll}1 / 71 & \text { R32x } \\ 1 / 79 & \text { R60 } \\ 1 / 154 & \text { R30 }\end{array}$

Roma, BAV siehe Vaticano, BAV

Rouen, BM:

$\begin{array}{ll}1355 & \text { R70 } \\ 3019 & \text { R26 }\end{array}$

's Gravenhage (Den Haag), Koninklijke

Bibliotheek:

73 G 5 R56a

San Candido (Innichen), Biblioteca della

Collegiata (StiftsB):
VIII. B. 8
R32k

VIII. B. 11

R32k

VIII. B. 13

R32s

VIII. C. 3

R32k

VIII. C. 8

R32e

VIII. C. 13

R321

Saint-Omer, BM:

$\begin{array}{ll}292 & \text { R36 } \\ 361 & \text { R36 } \\ 647 & \text { R56a }\end{array}$

Sankt Florian, StiftsB:

$\begin{array}{ll}\text { XI } 113 & \text { R34 } \\ \text { XI } 318 & \text { R40 }\end{array}$

Sankt Gallen, Kantonsbibliothek

(Vadiana):

Ink. $1480 \quad$ R56a 
Sankt Gallen, StiftsB:

$\begin{array}{ll}288 & \text { R61 } \\ 1008 & \text { R40 }\end{array}$

Sankt Paul im Lavanttal, StiftsB:
25.4.28
R34
Codices Blasiani
chartacei 79/4 R60

St. Petersburg (olim Leningrad), Archiv Leningradskogo otdelenija Instituta istorii Akademii Nauk SS: $1 / 614 \quad$ R60

Sankt Pölten, Diözesanbibliothek:

$\begin{array}{ll}67 & \text { R5a, R21 } \\ 83 & \text { R74b }\end{array}$

Salamanca, BU:

$\begin{array}{ll}1875 & \text { R32a } \\ 2274 & \text { R56b } \\ 2108 & \text { R39 }\end{array}$

Salzburg, StiftsB St. Peter: b VI $11 \quad$ R26

Sandomierz (Sandomir), Seminarium

Duchowne: $1806 \quad$ R56a

Schlägl, StiftsB: $56(821.200) \quad$ R21 69 (816b.167) R74b

Schwabach, Kirchenbibliothek: Bd. 7/25 R75a

Seitenstetten, StiftsB: 226

R6

Sélestat (Schlettstadt), Bibliothèque Humaniste: 116 R5

Semur-en-Auxois, BM: 25 (26) R48

Sevilla, Biblioteca Capitular y

Colombina:

$\begin{array}{ll}5-1-5 & \text { R47b } \\ 5-3-25 & \text { R60 } \\ 7-4-4 & \text { R59 } \\ 7-6-41 & \text { R32f } \\ 56-2-17 & \text { R78 } \\ 81-6-10 & \text { R56a } \\ 141-23-15 & \text { R76 }\end{array}$

Siena, Biblioteca Comunale:
G. X. 33
R56a

Siena, Convento dell'Osservanza ms. 15

R30 (Übers./Bearb.)

Soest, StB:

cod. $13 \quad$ R16

Stams, StiftsB:
60
R21

Strasbourg (Straßburg), Bibliothèque nationale et universitaire :

$\begin{array}{ll}31 \text { (lat. 29) } & \text { R21 } \\ 41 \text { (lat. 39) } & \text { R16 }\end{array}$

Stuttgart, WLB:

$\begin{array}{ll}\text { HB I 57 } & \text { R61 } \\ \text { HB I 103 } & \text { R21 } \\ \text { HB I 119 } & \text { R21 } \\ \text { HB I 243 } & \text { R21 } \\ \text { HB VII 22a } & \text { R61 } \\ \text { HB X 25 } & \text { R48 } \\ \text { HB XV 68 } & \text { R17 } \\ \text { theol. et philos. } \\ \text { qu. 22 } & \text { R61 }\end{array}$

Sydney, Fisher Library of the

University:

Nicholson $23 \quad$ R36

Tartu (Dorpat), Tartu Riikliku Ülikooli

Teaduslik Raamatukogu: Mscr. $286 \quad$ R56a

Terni, Biblioteca Comunale: $179 \quad$ R30

Toledo, Archivo y Biblioteca Capitular: $\begin{array}{ll}10-28 & \text { R48 } \\ 39-27 & \text { R22 }\end{array}$

Torino, Biblioteca Civica: 381 R56a

Torino, BNU:
H. III. 6
$\mathrm{R} 48$
H. III. 8
R60

Toulouse, BM:

$220 \quad$ R32i

$392 \quad$ R59

Tours, BM:

$436 \quad$ R38

Trier, Bibliothek der Abtei St. Matthias: Hs. Nr. I/3 R61

Trier, Bibliothek des Priesterseminars: 59 R61 


$\begin{array}{ll}\begin{array}{l}\text { Trier, StB: } \\ \text { 195 }\end{array} & \text { R61 } \\ 195 / 12144^{\circ} & \text { R17 } \\ 565 & \text { R21 } \\ 579 & \text { R30 } \\ 581 / 15198^{\circ} & \text { R17 } \\ 601 / 15378^{\circ} & \text { R56a } \\ 668 / 2368^{\circ} & \text { R56a } \\ 783 / 8288^{\circ} & \text { R63 } \\ 975 / 9234^{\circ} & \text { R5a } \\ 1974 & \text { R61 }\end{array}$

Trieste, Biblioteca Civica:

$\begin{array}{ll}\text { I } 4 & \text { R56b, R60 } \\ \text { I 22 } & \text { R56a } \\ \text { I 33 } & \text { R60 } \\ \text { II 5 } & \text { R60 }\end{array}$

Troyes, BM: 1495 R56a

Tübingen, UB:

$\begin{array}{ll}\text { Mc 122 } & \text { R56a } \\ \text { Mc } 127 & \text { R75a } \\ \text { Mc } 149 & \text { R49 }\end{array}$

Uncastillo, Colegiata de Santa María: códice 10 A9

Uppsala, UnB:

$\begin{array}{ll}\text { C 33 } & \text { R56a } \\ \text { C 73 } & \text { R38 } \\ \text { C 131 } & \text { R5a } \\ \text { C 204 } & \text { R48 } \\ \text { C 208 } & \text { R21 } \\ \text { C 216 } & \text { R21 } \\ \text { C 268 } & \text { R21 } \\ \text { C 391 } & \text { R21 } \\ \text { C 395 } & \text { R21 } \\ \text { C 605 } & \text { R56a } \\ \text { C 634 } & \text { R75a }\end{array}$

Utrecht, BR:

$\begin{array}{ll}204 & \text { R61 } \\ 218 & \text { R75b } \\ 259 & \text { R56a } \\ 340 & \text { R61 } \\ 383 & \text { R56a } \\ 1023 & \text { R61 (Übers./Bearb.) }\end{array}$

Vaticano, Archivio Segreto Vaticano:

Arm. LIV R68

Arm. LIV, 30 R68

Arm. LIV, $31 \quad$ R68, R69

Vaticano, BAV:

Barb. lat. $684 \quad$ R32f
Barb. lat. 872

Barb. lat. 1211

Barb. lat. 2110

Borgh. 29

Borgh. 102

Borgh. 205

Borgh. 291

Borgh. 347

Borgh. 545

Chigi J. IV. 118

Ottob. lat. 375

Ottob. lat. 405

Ottob. lat. 409

Ottob. lat. 704

Ottob. lat. 850

Ottob. lat. 858

Ottob. lat. 1220

Ottob. lat. 1278

Ottob. lat. 1405

Ottob. lat. 1761

Ottob. lat. 1908

Pal. lat. 327

Pal. lat. 363

Pal. lat. 397

Pal. lat. 399

Pal. lat. 725

Pal. lat. 955

Pal. lat. 970

Pal. lat. 1329

Pal. lat. 1332

Pal. lat. 1596

Pal. lat. 1730

Reg. lat. 297

Reg. lat. 323

Reg. lat. 1059

Ross. lat. 1124

Ross. 1128

Urbin. lat. 333

Urbin. lat. 1394

Urbin. lat. 1442

Vat. lat. 1033

Vat. lat. 1034

Vat. lat. 1035

Vat. lat. 1036

Vat. lat. 1122

Vat. lat. 1308

Vat. lat. 1309

Vat. lat. 1332

Vat. lat. 1666

Vat. lat. 2625

Vat. lat. 2973

Vat. lat. 3171

Vat. lat. 3824

Vat. lat. 3978
R78 (Fass.)

R78

R56a

R37

R78

R36

R22

R23

R321

R60

R32l, R32v'

R32v, R32x

R32s

R32r

R38 (Titel)

R38

R60

R79

R32o, R32r, R32v

R14

R56a

R60

R8

R40

R21

R74a

R20

R71a

R58

R39, R58

R56a

R56a

R57b

R33 (Dat.)

R37

R5

R60

R56a

R32i

R32i

R57a

R57a

R57a

R57a

R67a, R67b

R31

R31

R58

R71b, R71c

R5

R56a

R60

R36

R14, R15 
Vat. lat. 4039

Vat. lat. 4100

Vat. lat. 4153

Vat. lat. 4519

Vat. lat. 4853

Vat. lat. 4957

Vat. lat. 5044

Vat. lat. 5131

Vat. lat. 5146

Vat. lat. 5608

Vat. lat. 5732

Vat. lat. 7294

Vat. lat. 8078

Vat. lat. 9344

Vat. lat. 9832

Vat. lat. 10275

Vat. lat. 10499

Vat. lat. 10726

Vat. lat. 13680

Venezia, BNM:

Fondo Antico Lat. Z.

324 (=1938)

Fondo Antico Lat. Z. 475 (=1660)

Fondo Antico Lat. Z. 476 (=1944)

Fondo Antico Lat. Z. 495 (=1711)

Lat. I. $41(=2057)$

Lat. II 65 (=2901)

Lat. III. $116(=2208)$

Lat. III. 159 (=2624)

Lat. IV. $20(=2372)$

Lat. VI. $200(=2757)$

Lat. VI. 214 (=3598)

Lat. XI. 59 (=4152)

Lat. XIV. 127 (=4332)

Lat. XIV. 130 (=4335)

Lat. XIV. 224 (=4341)

Lat. XIV. $234(=4048)$

Lat. XIV. $239(=4500)$

Lat. XIV. 254 (=4535)

Venezia, Biblioteca Querini-Stampalia:

Classe IX n. 11
R45

R37

R68

R56b (Edit.)

R61

R20

R321

R60

R48

R68

R36

R56a

R60

R32a,

R32b,

R32d,

R32e,

R32g, R32k

R79

R79

R7a

R5b

R32j, R37

R39

R56b (Titel, Dat. u. Fass.)

R56a

R50

R32d

R7

R32d, R32g

R61

R37

R32d

R51

R60

R56a

R56a

R56a,

R71c,

R71d

R60

R60

R60

R7le
Venezia, Museo Civico Correr:

Fondo Cicogna 855

(1266)

R60

Verona, Biblioteca Capitolare:

CCXXVIII

(355) R60

Vorau, StiftsB:

$\begin{array}{ll}172 & \text { R48 } \\ 192 & \text { R56a } \\ 219 & \text { R48 }\end{array}$

Weimar, Thüringische LB:

Q 566 R26 (Übers.)

Weimar, Herzogin-Anna-Amalia-

Bibliothek (olim Zentralbibliothek der

Deutschen Klassik):

cod. Q $49 \quad$ R17

cod. Q 64 R52 (Autor)

Wien, Dominikanerkonvent:

$\begin{array}{ll}45 / 267 & \text { R40 } \\ 71 / 295 & \text { R6 } \\ 163 / 132 & \text { R21 } \\ 166 / 136 & \text { R56a } \\ & 196 / 161 \\ 231 / 258 & \text { R60 } \\ \text { H 1 MBK } & \text { R56a } \\ \text { H 23 MBK } & \text { R56a }\end{array}$

Wien, ÖNB:

362 R19, R26

$480 \quad$ R9 (Edit.)

812 R21

1352 R61, R74b

1387 R66a (Edit.), R66b

$1430 \quad$ R57b

3120 R56b

3449 R71a

3513 R56a

$3600 \quad \mathrm{R} 75 \mathrm{~b}$

$3711 \quad \mathrm{R} 74 \mathrm{~b}$

3719 R60

3799 R61

3803 R61

3930 R66b

3932 R66b

3939 R61

4018 R56a

4031 R61

$4127 \quad$ R57a

$4180 \quad$ R26

4505 R66b

$4516 \quad \mathrm{R} 66 \mathrm{~b}$ 


$\begin{array}{ll}4548 & \text { R61 } \\ 4659 & \text { R75a } \\ 4696 & \text { R59 } \\ 4751 & \text { R39 } \\ 4819 & \text { R57a } \\ 5509 & \text { R39 } \\ 8695 & \text { R9 } \\ 14447 & \text { R40 } \\ 14523 & \text { R61 } \\ 15040 & \text { R5a } \\ 15262 & \text { R61 } \\ 15417 & \text { R55 } \\ \text { (Übers./Bearb.) } & \end{array}$

Wien, Schottenkloster: 29 (50.c. 10)

R56a

Wilhering, StiftsB:

IX 101

R21

Wolfenbüttel, HAB: 33.1. Aug. fol. 50.2. Aug. fol.

11. Aug. qu.

19.12 Aug. qu.

23.19 Aug. qu.

23.22 Aug. qu.

Cod. Weiss. 96 (4180)

264.25 Extravagantes

152 Helmstedt

237 Helmstedt

272 Helmstedt

338 Helmstedt

552 Helmstedt

678 Helmstedt

Wrocław (Breslau), Biblioteka

Kapitulna:

114

R74b

Wrocław (Breslau), BUn,

I fol. 275

I fol. 244

I fol. 285

R29

R58

R3

R29

R29

R60

R29

R70

R61

R74b
I fol. 777

II fol. 36

I qu. 134

I qu. 94

I qu. 138

I. qu. 464

I G 315

IV qu. 41

R61

R67a

R61

R61

$\mathrm{R} 74 \mathrm{~b}$

R74b

$\mathrm{R} 40$

R61

R61

Rehdiger 119 R47a

Rehdiger $130 \quad$ R37

Rehdiger $342 \quad$ R20

Würzburg, UB:

M. ch. f. 5

$\mathrm{R} 5 \mathrm{~b}$

M. ch. f. 26

R61

M. ch. f. 60

R56b

$\mathrm{R} 46$

M. ch. f. 88

R60

h. f. 124

A 13

M. ch. q. $18 \quad$ R34

M. ch. q. $81 \quad$ R34

M. ch. q. $193 \quad$ R38

M. p. th. f. $55 \quad$ R5a

R29 Zagreb, Knjižnica Jugoslavenske

R32g Akademije Znanosti i Umjetnosti

R70 (Akademie der Künste und

Wissenschaften):

$$
\text { II.C.61 }
$$

R71a

Zeitz, StiftsB:

cod. 13a (Philos Nr. 5) R56b

cod. 13b (Philos Nr. 6) R56b

Zürich, Zentralbibliothek:

$\begin{array}{ll}\text { C. } 103 & \text { R56a } \\ \text { Car. C } 156 & \text { R60 }\end{array}$

Zwickau, Ratsschulbibliothek: XXIV V 10

R56b

R28 (Dat./ Zwolle, Municipaal Archief:

Bearb.)
R61 


\section{Frühdrucke}

Frühdrucke, nach denen die Repertoriumsnummer ohne weitere Präzisierung angegeben wird, finden sich dort unter „Überlieferung“. Bei Frühdrucken, die in anderen Rubriken vorkommen, wird nach der Repertoriumsnummer in Klammern darauf hingewiesen: Übers $<$ etzungen $>$, Bearb $<$ eitungen $>$, Fass $<$ ungen $>$.

Die Drucke sind nach den einschlägigen Katalogen sortiert. Auflösung der Abkürzungen auf S. xxvi-xxx.

\begin{tabular}{|c|c|c|c|}
\hline BSB-Ink & & GW Bd. 4, 419 & $\mathrm{R} 27$ \\
\hline BSB-Ink. B-209 & $\mathrm{R} 5 \mathrm{a}$ & GW Bd. 4, 419 & $\mathrm{R} 27$ \\
\hline BSB-Ink. B-210 & R5 & GW Bd. 7, 382. & R37 \\
\hline BSB-Ink. B-211 & R5b & GW Bd. 10, 518-519 & R38 \\
\hline BSB-Ink. B-212 & $\mathrm{R} 5 \mathrm{~b}$ & GW 2032 & R21 \\
\hline BSB-Ink. B-213 & R5b & GW 2033 & R21 \\
\hline BSB-Ink. B-511 & R21 & GW 2034 & $\mathrm{R} 21$ \\
\hline BSB-Ink. B-512 & R21 & GW 2040 & R21 \\
\hline BSB-Ink. B-513 & R21 & GW 2041 & R21 (Übers./ \\
\hline BSB-Ink. G-14 & R55 & & Bearb.) \\
\hline BSB Ink. G-15 & R55 & GW 2042 & R21 (Übers.) \\
\hline BSB-Ink. G-501 & R52 & & Bearb.) \\
\hline BSB-Ink. G-502 & R52 & GW 2099 & R38 \\
\hline BSB-Ink. I-172 & $\mathrm{R} 5 \mathrm{a}$ & GW 2100 & R38 \\
\hline BSB-Ink. I-523 & R61 & GW 3648 & R5a \\
\hline BSB-Ink. I-524 & $\mathrm{R} 61$ & GW 3652 & $\mathrm{R} 5 \mathrm{c}$ \\
\hline BSB-Ink. I-525 & R61 & GW 3653 & $\mathrm{R} 5 \mathrm{c}$ \\
\hline BSB-Ink. L-284 & R32f, R32n, R32t & GW 3655 & R5c (Übers./ \\
\hline BSB-Ink. L-285 & R32i & & Bearb.) \\
\hline BSB-Ink. M-267 & R75a & GW 3656 & R5c (Übers.) \\
\hline BSB-Ink. M-268 & R75a & & Bearb.) \\
\hline BSB-Ink. M-269 & R75a & GW 4644 & R27 \\
\hline BSB-Ink. M-270 & R75a & GW 4646 & R27 \\
\hline BSB-Ink. M-271 & R75a & GW 4647 & R27 \\
\hline BSB-Ink. P-798 & $\mathrm{R} 5 \mathrm{c}$ & GW 4648 & $\mathrm{R} 27$ \\
\hline BSB-Ink. P-799 & $\mathrm{R} 5 \mathrm{c}$ & GW 4649 & $\mathrm{R} 27$ \\
\hline BSB-Ink. T-141 & R49 & GW 4686 & R27 \\
\hline BSB-Ink. T-142 & $\mathrm{R} 49$ & GW 4687 & $\mathrm{R} 27$ \\
\hline BSB-Ink. T-143 & R49 & GW 4688 & $\mathrm{R} 27$ \\
\hline BSB-Ink. T-144 & R49 & GW 4689 & $\mathrm{R} 27$ \\
\hline BSB-Ink. T-145 & R49 & GW 4690 & R27 \\
\hline BSB-Ink. T-146 & R49 & GW 4691 & R27 \\
\hline BSB-Ink. T-147 & $\mathrm{R} 49$ & GW 4692 & R27 \\
\hline & & GW 4693 & R27 \\
\hline $\mathrm{C}$ & & GW 5880 & R16 \\
\hline C 903 & R5 & GW 5881 & R16 \\
\hline C 1488 & $\mathrm{R} 22$ & GW 6226 & Ala \\
\hline C 1956 & $\mathrm{R} 48$ & & (Editionen) \\
\hline C 2877 & R38 & GW 8261 & R37 \\
\hline C 4709 & R60 & GW 8262 & R37 \\
\hline C 5773 & R21 & GW 8263 & R37 \\
\hline & & GW 8264 & R37 \\
\hline GW & & GW 8265 & R37 \\
\hline GW Bd. 3, 540 & R5a & GW 8266 & R37 \\
\hline GW Bd. 3, 541 & R5 & GW 8267 & R37 \\
\hline
\end{tabular}




$\begin{array}{ll}\text { GW 8268 } & \text { R37 } \\ \text { GW 8269 } & \text { R37 } \\ \text { GW 8270 } & \text { R37 } \\ \text { GW 8271 } & \text { R37 } \\ \text { GW 8272 } & \text { R37 } \\ \text { GW 8273 } & \text { R37 } \\ \text { GW 8479 } & \text { R77 } \\ \text { GW 8480 } & \text { R77 } \\ \text { GW 8481 } & \text { R77 } \\ \text { GW 10941 } & \text { R46 } \\ \text { GW 10942 } & \text { R46 } \\ \text { GW 10943 } & \text { R46 } \\ \text { GW 11709 } & \text { R22 } \\ \text { GW 11710 } & \text { R22 } \\ \text { GW 11711 } & \text { R22 } \\ \text { GW 11712 } & \text { R22 } \\ \text { GW 11713 } & \text { R22 } \\ \text { GW 11714 } & \text { R22 } \\ \text { GW 11715 } & \text { R22 } \\ \text { GW 12026 } & \text { R38 } \\ \text { GW 12027 } & \text { R38 } \\ \text { GW 12028 } & \text { R38 } \\ \text { GW 12029 } & \text { R38 } \\ \text { GW 12030 } & \text { R38 } \\ \text { GW 12031 } & \text { R38 } \\ \text { GW 12032 } & \text { R38 } \\ \text { GW 12033 } & \text { R38 } \\ \text { GW 12034 } & \text { R38 } \\ \text { GW 12035 } & \text { R38 } \\ \text { GW 12036 } & \text { R38 } \\ \text { GW 12037 } & \text { R38 } \\ \text { GW 12038 } & \text { R38 } \\ \text { GW 12039 } & \text { R38 } \\ \text { GW 12040 } & \text { R38 } \\ \text { GW 12041 } & \text { R38 } \\ \text { GW 12042 } & \text { R38 } \\ \text { GW 12043 } & \text { R38 } \\ \text { GW 12044 } & \text { R38 } \\ \text { GW 12045 } & \text { R38 } \\ & \end{array}$

Geiß

$\begin{array}{ll}\text { Geiß 1 } & \text { R56a, R56b } \\ \text { Geiß 2. } & \text { R56a } \\ \text { Geiß 3 } & \text { R56a, R56b } \\ \text { Geiß 58-66 } & \text { R56b } \\ \text { Geiß 71 } & \text { R56a } \\ \text { Geiß 72 } & \text { R56a } \\ \text { Geiß 73 } & \text { R56a } \\ \text { Geiß 74 } & \text { R56a } \\ \text { Geiß 76 } & \text { R56b (Übers./ } \\ & \text { Bearb.) } \\ \text { Geiß 77 } & \text { R56b (Übers./ } \\ & \text { Bearb.) } \\ \text { Geiß 78 } & \text { R56b (Übers./ } \\ & \text { Bearb.) }\end{array}$

Geiß $80 \quad$ R60

Geiß $81 \quad$ R60

Geiß 82 R60

Geiß $83 \quad$ R60

Geiß $84 \quad$ R60

Geiß $85 \quad$ R60

Geiß $86 \quad$ R60

Geiß $87 \quad$ R60

H, HC, HCR

HC $654(=\mathrm{H} 6131) \quad \mathrm{R} 48$

H 1139 (2.3) R21

H $1140(2.3) \quad$ R21

HC 2642 R5a

HCR 2643 (?) R5b

H 2647 R5b

HC $2900 \quad$ R61

H $3463 \quad$ R27

H $3464 \quad$ R27

HC $3465 \quad$ R27

HC $3467 \quad$ R27

HC $3468 \quad$ R27

H $3483 \quad$ R27

HC $3485 \quad$ R27

H $3486 \quad$ R27

H $3487 \quad$ R27

$\begin{array}{ll}\text { HC } 3488 & \text { R27 }\end{array}$

HCR $3489 \quad$ R27

H $3497 \quad$ R27

H 4663 R22

H $4664 \quad$ R22

HC $4665 \quad$ R22

HC $4666 \quad$ R22

H $5803 \quad$ R75a

H $5804 \quad$ R75a

HC $5805 \quad$ R75a

HC $5806 \quad$ R75a

HC $5807 \quad$ R75a

H $5808 \quad$ R75a

H $5809 \quad$ R75a

HC $6112 \quad$ R37

HC $6124 \quad$ R48

HC $6125 \quad$ R48

HC $6126 \quad$ R48

HC $6127 \quad$ R48

HC $6128 \quad$ R48

HC $6129 \quad$ R48

H 6131 (=HC 654) R48

HC 6135 R48 (Übers.)

HC 6136 R48 (Übers.)

HC 6137 R48 (Übers.)

H $7449=$ H $11654 \quad$ R55

H $7450 \quad$ R55

HC $7451 \quad$ R55 


\begin{tabular}{|c|c|c|c|}
\hline HC 8389 & $\mathrm{R} 75 \mathrm{a}$ & Rogent/Duran 66 & R79 \\
\hline H 8589 & $\mathrm{R} 5 \mathrm{~b}$ & Rogent/Duran 67 & $\mathrm{R} 32 \mathrm{O}$ \\
\hline H 10210 & $\mathrm{R} 5 \mathrm{~A}$ & Rogent/Duran 144 & $\mathrm{R} 32 \mathrm{o}$ \\
\hline HC 10324 & $\mathrm{R} 32 \mathrm{i}$ & & (Editionen) \\
\hline \multirow[t]{3}{*}{ HC 10327 (= H 13029) } & R32f, & Rogent/Duran 162 & R32o \\
\hline & $\mathrm{R} 32 \mathrm{n}$ & & (Editionen) \\
\hline & $\mathrm{R} 32 \mathrm{t}$ & Rogent/Duran 180 & $\mathrm{R} 320$ \\
\hline HC 11937 & R52 & & (Editionen) \\
\hline HC 11938 & R52 & Rogent/Duran 233 & $\mathrm{R} 32 \mathrm{o}$ \\
\hline HC 11946 & R52 & & (Editionen) \\
\hline HC 12749 & R56a & Rogent/Duran 332 & R32o \\
\hline HCR 12797 & $\mathrm{R} 60$ & & (Editionen), \\
\hline H 12800 & R56a & & $\mathrm{R} 32 \mathrm{r}$ \\
\hline HC 12801 & R56a & & (Editionen) \\
\hline HC 12802 & R56a & Rogent/Duran 67 & $\mathrm{R} 32 \mathrm{o}$ \\
\hline HGR 12829 & R56a & & (Editionen) \\
\hline HC 12910 & $\mathrm{R} 49$ & Rogent/Duran 371 & R32f (Übers./ \\
\hline H 12911 & $\mathrm{R} 49$ & & Bearb.) \\
\hline HC 12912 & $\mathrm{R} 49$ & & \\
\hline HC 12913 & $\mathrm{R} 49$ & VD 16 & \\
\hline H 12914 & $\mathrm{R} 49$ & VD 16 A 1337 & R35 \\
\hline HC 12915 & $\mathrm{R} 49$ & VD 16 A 2906 & $\mathrm{R} 21$ \\
\hline HC 12916 & $\mathrm{R} 49$ & VD 16 A 2908 & R21 \\
\hline HC 15235 & $\mathrm{R} 61$ & VD 16 A 2909 & $\mathrm{R} 21$ \\
\hline $\mathrm{HC}(+$ Add $) 15236$ & $\mathrm{R} 61$ & VD 16 A 2910 & $\mathrm{R} 21$ \\
\hline HC 15237 & $\mathrm{R} 61$ & VD 16 A 2911 & $\mathrm{R} 21$ \\
\hline HC 15238 & $\mathrm{R} 62$ & VD 16 A 2912 & $\mathrm{R} 21$ \\
\hline HG 15543 & $\mathrm{R} 46$ & VD 16 B 576 & $\mathrm{R} 5 \mathrm{c}$ \\
\hline \multirow[t]{3}{*}{ H 16076} & $\mathrm{R} 61$ & VD 16 B 581 & \\
\hline & (Übers./ & $(=\mathrm{VD} 16$ B 597, & \\
\hline & Bearb.) & VD 16 B 607) & R5a \\
\hline H $11654=$ H 7449 & R55 & VD 16 B 582 & \\
\hline \multirow[t]{3}{*}{ H 13029 (= HC 10327) } & R32f, & (= VD 16 B 598, & \\
\hline & R32n, & VD 16 B 608) & $\mathrm{R} 5 \mathrm{a}$ \\
\hline & $\mathrm{R} 32 \mathrm{t}$ & $\begin{array}{l}\text { VD } 16 \text { B } 583 \\
=\text { VD } 16 \text { B } 599\end{array}$ & \\
\hline GI & & VD 16 B 609) & $\mathrm{R} 5 \mathrm{a}$ \\
\hline IGI 7568 & $\mathrm{R} 60$ & VD 16 B 584 & \\
\hline \multirow[t]{2}{*}{ IGI 5801} & R60 & (=VD 16 B 600, & \\
\hline & & VD 16 B 610) & R5a \\
\hline \multicolumn{2}{|l|}{ Rogent/Duran } & VD 16 B 585 & \\
\hline Rogent/Duran 16 & R79 & $(=\mathrm{VD} 16 \mathrm{~B} 601)$ & R5a \\
\hline Rogent/Duran 18 & $\mathrm{R} 32 \mathrm{i}$ & VD 16 B 586 & \\
\hline \multirow[t]{3}{*}{ Rogent/Duran 24} & R32f, & $(=\mathrm{VD} 16$ B 602$)$ & R5a \\
\hline & R32n, & VD 16 B 588 & \\
\hline & $\mathrm{R} 32 \mathrm{t}$ & $(=\mathrm{VD} 16$ B 604 , & \\
\hline \multirow[t]{3}{*}{ Rogent/Duran 25} & R32f, & VD 16 B 614) & R5a \\
\hline & $\mathrm{R} 32 \mathrm{n}$ & VD 16 B 590 & R5a \\
\hline & $\mathrm{R} 32 \mathrm{t}$ & VD 16 B 591 & $\mathrm{R} 5 \mathrm{a}$ \\
\hline Rogent/Duran 38 & $\mathrm{R} 32 \mathrm{i}$ & VD 16 B 605 & \\
\hline \multirow[t]{2}{*}{ Rogent/Duran 42} & R32g, & $(=\mathrm{VD} 16 \mathrm{~B} 615)$ & R5a \\
\hline & R321 & VD 16 B 606 & \\
\hline Rogent/Duran 47 & $\mathrm{R} 32 \mathrm{k}$ & $(=\mathrm{VD} 16 \mathrm{~B} 616)$ & R5a \\
\hline Rogent/Duran 58 & $\mathrm{R} 32 \mathrm{o}$ & VD 16 C 94 & $\mathrm{R} 16$ \\
\hline
\end{tabular}




\begin{tabular}{|c|c|}
\hline VD 16 C 95 & R16 \\
\hline VD 16 C 1571 & $\begin{array}{l}\text { Ala } \\
\text { (Editionen) }\end{array}$ \\
\hline VD 16 D 1351 & R37 \\
\hline VD 16 D 1352 & R37 \\
\hline VD 16 D 1353 & $\begin{array}{l}\text { R37 (Übers./ } \\
\text { Bearb.) }\end{array}$ \\
\hline VD 16 G 4073 & R38 \\
\hline VD $16 \mathrm{~J} 541$ & R61 \\
\hline VD $16 \mathrm{~J} 542$ & $\mathrm{R} 61$ \\
\hline
\end{tabular}

$\begin{array}{ll}\text { VD 16 J } 543 & \text { R61 } \\ \text { VD 16 J 544 } & \text { R61 } \\ \text { VD 16 N } 1562 & \text { R48 } \\ \text { VD 16 P } 2434 & \text { R49 } \\ \text { VD 16 P 2435 } & \text { R49 } \\ \text { VD 16 P 2436 } & \text { R49 } \\ \text { VD 16 P 2437 } & \text { R49 } \\ \text { VD 16 T } 337-T \text { T 552 } & \text { R5c (Übers./ } \\ & \text { Bearb.) } \\ \text { VD 16 W } 4688 & \text { R66b }\end{array}$




\section{Konkordanzen zu anderen Repertorien}

Die Repertorien und Kataloge werden hier abgekürzt zitiert. Auflösung der Abkürzungen S. $\mathrm{xxvi}^{-} \mathrm{xxx}$.

\section{BibCarm}

Bd. 2, 4-8 (VII) R62

Bloomfield

0858 R16

0874

1158

1306

1942

3136

4714

5403

5603

5722

Bonner

FD II.22

II.A. 4

II.A. 11

II.A. 20

II.B. 13

II.B. 15

III. 7

III. 14

III. 30

III. 31

III.33

III.58

III.81

IV.33

IV.34

IV.35

IV.36

IV.37

IV.40

IV.45

IV.49

IV.53

IV.73

IV.97

IV.108

Bonner2

Bonner-2 II.A.6

Bonner-2 II.A.9

Bonner-2 II.A.18

Bonner-2 II.B.13

Bonner-2 II.B.12
R34

R54

R53

R36

R75a

R8

R74b

R34

R48

R79

R32a

R32b

R32c

R32d

R32e

R32f

R32g

R32h

R32i

R32j

R32k

R32l

R32m

R32n

R32o

R32p

R32q

R32r

R32s

R32t

R32u

R32v

R32w

R32x

R32b

R32a

R32c

R32e

R32d

\section{CALMA}

Alberta 1, 2 R24

Alberti 4, $8 \quad$ R47

Arn 41, 2 R28

Arna 24, 42 R36

Coing

221

R22

DCist

170-172 R16

$271 \quad$ R55

315-316 R72

$534 \quad$ A7

$571 \quad$ R55

$607 \quad \mathrm{R} 17$

De Visch 57-61 R16

58-60 R11

117-118 R55

$136 \quad$ R72

$276 \quad$ R55

285-286 R17

Díaz

935 R43

1214 A9

1629 R36

$1746 \quad$ R32b

$1748 \quad$ R32a

1757 R32d

$1758 \quad$ R32e

1771 R32c

$1778 \quad$ R32g

$1790 \quad$ R32h

1791 R32i

1795 R32j

1813 R32k

1836 R32l

1868 R32r

1872 R32n

1873 R32m

1875 R32o

1876 R32p

$1877 \quad$ R32q

1886 R32s

1889 R32t 


\begin{tabular}{|c|c|c|c|}
\hline 1893 & $\mathrm{R} 32 \mathrm{u}$ & 15 & R71d \\
\hline 1907 & $\mathrm{R} 32 \mathrm{v}$ & 17 & R7 le \\
\hline 1928 & $\mathrm{R} 32 \mathrm{w}$ & & \\
\hline 1941 & $\mathrm{R} 32 \mathrm{x}$ & $\begin{array}{l}\text { Labrosse } \\
36\end{array}$ & R26 \\
\hline Distelbrink & & & \\
\hline 125 & R29 & Llull-DB & \\
\hline 23 & $\mathrm{R} 27$ & AdvMes & $\mathrm{R} 32 \mathrm{c}$ \\
\hline & & CincSav & $\mathrm{R} 32 \mathrm{~g}$ \\
\hline Glorieux, $A r t$ & & GivMun & R32x \\
\hline $14 \mathrm{cu}$ & R35 & ConcVirg & R79 \\
\hline & & ConsErm & $\mathrm{R} 32 \mathrm{v}$ \\
\hline Glorieux, Th & ogie & ConsVen & R32j \\
\hline I. $211(\mathrm{bi})$ & R36 & Contrad & $\mathrm{R} 32 \mathrm{p}$ \\
\hline $6 \mathrm{cu}$ & R35 & DeclRaym & $\mathrm{R} 32 \mathrm{~h}$ \\
\hline $316 \mathrm{ba}$ & R29 & DeoMaj & R32w \\
\hline 335 & R32j & DisFiInf & R32e \\
\hline 335am & R32d & DisFiInt & R32k \\
\hline $335 \mathrm{aq}$ & $\mathrm{R} 32 \mathrm{e}$ & DispAver & $\mathrm{R} 32 \mathrm{~m}$ \\
\hline $335 \mathrm{az}$ & R32f & DispEr & R32i \\
\hline 335bi & R32g & DispHam & R32l \\
\hline 335bu & R32h & Efficien & R32r \\
\hline $335 \mathrm{bv}$ & R32i & Gentil & $\mathrm{R} 32 \mathrm{a}$ \\
\hline $335 c x$ & R32k & Lament & R32o \\
\hline $335 \mathrm{ds} / \mathrm{hs}$ & R321 & LocAng & R32u \\
\hline $335 \mathrm{ew}$ & R32r & Natalis & R32n \\
\hline $335 \mathrm{fa}$ & $\mathrm{R} 32 \mathrm{n}$ & Phantas & R32t \\
\hline $335 \mathrm{fb}$ & $\mathrm{R} 32 \mathrm{~m}$ & PsalmQui & $\mathrm{R} 32 \mathrm{~d}$ \\
\hline $335 \mathrm{fd}$ & R32o & Qvalde & R32s \\
\hline $335 \mathrm{fe}$ & R32p & SaMaria & R32f \\
\hline $335 \mathrm{ff}$ & R32q & SancSpir & R32b \\
\hline 335 fo & R32s & SyllCont & R32q \\
\hline $335 \mathrm{fr}$ & R32t & & \\
\hline $335 \mathrm{gj}$ & $\mathrm{R} 32 \mathrm{v}$ & Meier & \\
\hline 335he & R32w & $100(83)$ & R3 \\
\hline $335 \mathrm{hr}$ & R32x & & \\
\hline $335 \mathrm{ie}$ & R32c & Mohan & \\
\hline $335 o$ & R32b & $43^{*}$ & R41 \\
\hline $335 q$ & R32a & $94^{*}$ & R53 \\
\hline & & $152^{*}$ & R44 \\
\hline Gruys & & $230 *$ & R29 \\
\hline 134 & R74a, R74b & $296^{*}$ & R37 \\
\hline & & 355 & R50 \\
\hline Heimann & & $478^{*}$ & R23 \\
\hline 21 & R76 & & \\
\hline & & Niesner & \\
\hline Hohmann & & 26 & R32a \\
\hline 72 & R70 & 32 & R59 \\
\hline Kohl & & Pereira, Arnaldo & \\
\hline 4 & R71a & 138 & R39 \\
\hline 8 & R71b & 147 & R58 \\
\hline 9 & R71c & & \\
\hline
\end{tabular}




$\begin{array}{cl}\text { Platzeck } & \\ 6 & \text { R32a } \\ 13 & \text { R32b } \\ 46 & \text { R32d } \\ 49 & \text { R32e } \\ 60 & \text { R32f } \\ 62 & \text { R32c } \\ 72 & \text { R32g } \\ 86 & \text { R32h } \\ 87 & \text { R32i } \\ 89 & \text { R32j } \\ 117 & \text { R32k } \\ 147 & \text { R32l } \\ 186 & \text { R32m } \\ 187 & \text { R32n } \\ 188 & \text { R32p } \\ 189 & \text { R32q } \\ 191 & \text { R32o } \\ 194 & \text { R32r } \\ 199 & \text { R32s } \\ 210 & \text { R32t } \\ 213 & \text { R32u } \\ 233 & \text { R32v } \\ 259 & \text { R32w } \\ 269 & \text { R32x }\end{array}$

Porębski $101(85) \quad$ R3

Prodromus

II§VI R26

RepFont

1,403

2, 168

3, 101-102

3, 206

3, 207

3,276

4, 187-188

4, 188-189

4, 310

5,138

5,274

$5,430-434$

5,581

$6,244-245$

$6,340-342$

$6,387-390$

6,537

7, 388-389

7, 433

7, 514-515

7, 647-649
R28

R24

R16

Ala

Alb

R55

R40

R11

R37

R7le

Ala

R70

R30

R8

R67a, R67b

R29

R68

Ala

A3

R75a

R47
8, 315-321

8,317

$8,587-588$

8, 593-594

9, 130-131

9, 164

9, 189-191

10, 106-107

R52

R37

R56b

R56a

R43

R59

A22

R57a,

R57b

\section{ROL op.}

ROL op. $11 \quad$ R32a

ROL op. 18 R32b

ROL op. $20 \quad$ R32c

ROL op. 39 R32d

ROL op. $40 \quad$ R32e

ROL op. $49 \quad$ R32f

ROL op. $56 \quad$ R32g

ROL op. 74* R32h

ROL op. $76 \quad$ R32i

ROL op. $78 \quad$ R32j

ROL op. 105 R32k

ROL op. $131 \quad$ R32l

ROL op. $168 \quad$ R32m

ROL op. $169 \quad$ R32n

ROL op. $170 \quad$ R32o

ROL op. $171 \quad$ R32p

ROL op. $172 \quad$ R32q

ROL op. $175 \quad$ R32r

ROL op. 181 R32s

ROL op. $190 \quad$ R32t

ROL op. 194 R32u

ROL op. $214 \quad$ R32v,

R32v'

$\begin{array}{ll}\text { ROL op. } 239 & \text { R32w } \\ \text { ROL op. } 250 & \text { R32x }\end{array}$

Sbaralea

I, $61 \quad$ R32p

I. $62 \quad$ R32k

I, 157 (n.29) R27

III, 98-99 A21

MDCXXI.780 R25

$\begin{array}{ll}\text { MDCCII.836 R52 } & \text { R35 }\end{array}$

MDCCCLXXVI.935 R30

MMCGCXLIII. $1214 \quad$ R29

MMMCCCXLVIII.1746, $67 \quad$ R32o

MMMCCCXLVIII.1746, 111 R32n

MMMCCCXLVIII.1746, 158 R32v

MMMCCCXLVIII.1746, $180 \quad$ R32x

MMMCCCXLVIII.1746, $184 \quad$ R32a

MMMCCCXLVIII.1746, $187 \quad$ R32r

MMMCCCXLVIII.1746, $188 \quad$ R32m

MMMCCCXLVIII.1746, 189 R32p 


\begin{tabular}{|c|c|c|c|}
\hline MMMCCCXLVIII. 1746, 190 & $\mathrm{R} 32 \mathrm{q}$ & 1852 & R54 \\
\hline MMMCCCXLVIII.1 1746, 192 & R32s & 2198 & R31 \\
\hline MMMCGCXLVIII.1746, 193 & $\mathrm{R} 32 \mathrm{k}$ & 2256 & R61 \\
\hline MMMCCCXLVIII. 1746, 201 & R321 & 2370 & $\mathrm{R} 46$ \\
\hline MMMCCCXLVIII. 1746, 202 & R32g & 2506 & R78 \\
\hline MMMCCCXLVIII.1 1746, 204 & R32h & $3033-3036$ & $\mathrm{R} 26$ \\
\hline MMMCCCXLVIII. 1746, 205 & R32k & 3080 & R76 \\
\hline MMMCCCXLVIII. 1746, 207 & R32b & 3197 & A20 \\
\hline MMMCCCXLVIII. 1746, 215b & R32s & 3310 & R59 \\
\hline MMMCGCXLVIII.1746, 220 & $\mathrm{R} 32 \mathrm{c}$ & $3420-23$ & Ala \\
\hline MMMCGCXLVIII. 1746, 223 & $\mathrm{R} 32 \mathrm{t}$ & 3613 & R35 \\
\hline MMMCGCXLVIII. 1746, 228 & R32i & & \\
\hline MMMCCCXLVIII. 1746, 274 & R32w & Spunar & \\
\hline MMMCCCXLVIIII. 1746, 283 & R32u & 82 & $\mathrm{R} 67 \mathrm{~b}$ \\
\hline MMMCCCXLVIII. 1746, 300 & R32d & 84 & $\mathrm{R} 67 \mathrm{a}$ \\
\hline MMMCCCXLVIII. 1746, 304a & R32e & 151 & $\mathrm{R} 74 \mathrm{a}$ \\
\hline MMMCCCXLVIII. 1746,310 & R32i & 153 & $\mathrm{R} 74 \mathrm{~b}$ \\
\hline MMMCCCXLVIII. 1746, 333 & R32j & & \\
\hline MMMCCCLXV.1753 & $\mathrm{R} 44$ & Thomson & \\
\hline MMMCCCLXIX. 1759 & All & 47 & $\mathrm{R} 66 \mathrm{~b}$ \\
\hline MMMDXCI & R23 & 408. E 4 & $\mathrm{R} 66 \mathrm{a}$ \\
\hline Schreckenberg & & Thorndike/K & \\
\hline $3,317-318$ & R33 & 134 & A2 \\
\hline $3,318-321$ & R25 & 436 & R39 \\
\hline 3,321 & R26 & 572 & R51 \\
\hline \multirow[t]{2}{*}{3,372} & R59 & 678 & R39 \\
\hline & & 876 & A5 \\
\hline Sharpe & & $1407-8$ & R39 \\
\hline 270 & R18 & 1612 & R58 \\
\hline 839 & R29 & & \\
\hline \multirow[t]{2}{*}{986} & R66a, & Von Perger & \\
\hline & R66b & 41.10 & R21 \\
\hline 1110 & R65 & 48 & A3 \\
\hline 1174 & $\mathrm{R} 12$ & 79 & R8 \\
\hline 1305 & R44 & 80 & R17 \\
\hline \multirow[t]{2}{*}{1329} & R57a, & 81 & $\mathrm{R} 12$ \\
\hline & R57b & 82 & R16 \\
\hline 1355 & A3 & 83 & $\mathrm{R} 27$ \\
\hline 1372 & All 1 & 85 & A12 \\
\hline 1455 & R50 & 86 & R31 \\
\hline 2136 & R52 & 87 & A14 \\
\hline \multirow[t]{2}{*}{2157} & R72 & 88 & R29 \\
\hline & & 89 & R35 \\
\hline Singer & & 90 & R36 \\
\hline $1-10$ & A2 & 91.1 & R32a \\
\hline 229 & R39 & 91.2 & $\mathrm{R} 32 \mathrm{~b}$ \\
\hline \multirow[t]{2}{*}{355} & R58 & 91.3 & R32c \\
\hline & & 91.4 & R32d \\
\hline SOPMA & & 91.5 & R32e \\
\hline 703 & A23 & 91.7 & R32f \\
\hline 922 & R45 & 91.8. & R32g \\
\hline 1609 & A14 & 91.10 & R32h \\
\hline 1618 & R38 & 91.11 & R32i \\
\hline
\end{tabular}


KONKORDANZEN ZU ANDEREN REPERTORIEN

$\begin{array}{llcl}91.13 & \text { R32k } & 108 & \text { A15 } \\ 91.14 & \text { R32l } & 109.1 & \text { R57a } \\ 91.15 & \text { R32m } & 109.2 & \text { R57b } \\ 91.16 & \text { R32s } & 110 & \text { R72 } \\ 91.17 & \text { R32t } & 111.1 & \text { R66a } \\ 91.18 & \text { R32u } & 111.2 & \text { R66b } \\ 91.19 & \text { R32v } & 112 & \text { R70 } \\ 91.20 & \text { R32w } & 113.1 & \text { R74a } \\ 91.21 & \text { R32x } & 113.2 & \text { R74b } \\ 92 & \text { R33 } & 115.1 & \text { R71a } \\ 93 & \text { R25 } & 115.2 & \text { R71b } \\ 94 & \text { R26 } & 115.3 & \text { R71c } \\ 95 & \text { R37 } & 115.4 & \text { R71e } \\ 96 & \text { R34 } & 116.1 & \text { R75a } \\ 97 & \text { A4 } & 116.2 & \text { R75b } \\ 98 & \text { R44 } & 132.3 & \text { R3 } \\ 99.1 & \text { R52 } & \text { Wadding } & \\ 100 & \text { R53 } & 106-107 & \text { R52 } \\ 101.3 & \text { R54 } & 121 & \text { R30 } \\ 102 & \text { A13 } & 147-148 & \text { R29 } \\ 103 & \text { R59 } & 203 & \text { R44 } \\ 104 & \text { R64 } & 204 & \text { A11 } \\ 105.1 & \text { R56a } & & \\ 105.2 & \text { R56b } & \text { Weijers } & \\ 106 & \text { R60 } & 1,69 & \text { R28 } \\ 107 & \text { R62 } & & \end{array}$




\section{MITTELLATEINISCHE STUDIEN UND TEXTE}

1. Metellus von Tegernsee. Die "Quirinalien". Untersuchungen und Text 1965. Jacobsen (Ed.).

2. Pseudo-Ovidius. De vetula. Untersuchungen und Text. Klopsch (Ed.). 1967. ISBN 9004014640

3. Lange. Philologische Studien zur Latinität west-hispanischer Privaturkunden des 9.-12. Jahrhunderts. Langosch (Ed.). 1966. ISBN 9004014659

4. Joseph Iscanus. Werke und Briefe. Gompf (Ed.). 1970. ISBN 9004014667

5. Numen litterarum: the Old and New in Latin Poetry. Witke (Ed.). 1971.

6. Theobald. Physiologus. Edited with introduction, critical apparatus, translation and commentary by P.T. Eden. 1972. ISBN 9004034447

7. Geoffrey of Vitry. The commentary of Geoffrey of Vitry on Claudian De Raptu Proserpinae. Transcribed by A.K. Clarke and P.M. Giles with an introduction and notes by A.K. Clarke. 1973. ISBN 9004036741

8. Könsgen, E. Epistolae duorum amantium. Briefe Abaelards und Heloïses? Edition und Untersuchungen. 1974. ISBN 9004038752

9. Dronke, P. Fabula. Explorations into the uses of myth in medieval Platonism. Reprint 1985. ISBN 9004077154

10. Jacobsen, P.C. Flodoard von Reims. Sein Leben und seine Dichtung De Triumphis Christi. 1978. ISBN 9004054073

11. Langosch, K. Donisii Comedia Pamphile. Untersuchungen und Text. 1979. ISBN 9004060073

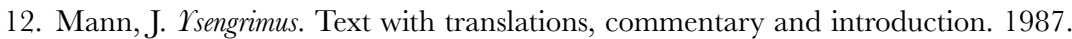
ISBN 9004081038

13. Petrus Presbyter. Carmina. Text und Kommentar. Herausgegeben von M. Rener. 1988. ISBN 9004087974

14. Nigel of Canterbury. The Passion of St. Lawrence, Epigrams and Marginal Poems. Edited and translated by J. M. Ziolkowski. ISBN 9004088652

15. Orbàn, A.P. Novus Phisiologus. Nach Hs. Darmstadt 2780. 1989. ISBN 9004088946

16. Hilarius Aurelianensis. Versus et Ludi epistolae. Ludus Danielis Belouacensis. [Die Egerton Handschrift]. Bemerkungen zur Musik des Daniel-Spiels von Beauvais von M. Bielitz. 1989. ISBN 9004090703

17. Unterkircher, F. (Ed.). Hugo von Lüttich: Peregrinarius. 1991. ISBN 9004093257

18. Hugo von Mâcon. Die Gesta Militum. Ein bisher unbekanntes Werk der Erzählliteratur des Hochmittelalters. Herausgegeben von E. Könsgen. 1990.

ISBN 9004092013

19. Harting-Corrêa, A. Walahfrid Strabo's Libellus de Exordiis et Incrementis. 1996.

ISBN 9004096698.

20. Westra, H.J. (Ed.). The Berlin Commentary on Martianus Capella's De Nuptiis Philologiae et Mercurii. Book I. With the Assistance of C. Vester. 1994.

ISBN 9004101705

21. Mann, N. \& B. Munk Olsen (Eds.). Medieval and Renaissance Scholarship. Proceedings of the Second European Science Foundation Workshop on the Classical Tradition in the Middle Ages and the Renaissance (London, Warburg Institute, 27-28 November 1992). 1997. ISBN 9004105085

22. Haye, T. Das lateinische Lehrgedicht im Mittelalter. Analyse einer Gattung. 1997. ISBN 9004106685

23. Westra, H.J. \& T. Kupke (Eds.). The Berlin Commentary on Martianus Capella's De Nuptiis Philologiae et Mercurii. Book II. With the Assistance of B. Garstad. 1998. ISBN 9004109684 
24. Ricklin, T. Der Traum der Philosophie im 12. Fahrhundert. Traum zwischen Constantinus Africanus und Aristoteles. 1999. ISBN 9004111166

25. Stein, E. Clericus in Speculo. Studien zur lateinischen Verssatire des 12. und 13. Jahrhunderts und Erstedition des "Speculum prelatorum". 1999. ISBN 9004113290

26. Meckelnborg, C. und B. Schneider. Opusculum fabularum. Die Fabelsammlung der Berliner Handschrift Theol. lat. fol. 142. 1999. ISBN 9004113339

27. Haye, T. Oratio. Mittelalterliche Redekunst in lateinischer Sprache. 1999. ISBN 9004113355

28. Murgatroyd, P. The Amatory Elegies of Johannes Secundus. 2000. ISBN 9004116036

29. Marenbon, P.G. (Ed.) Poetry and Philosophy in the Middle Ages. A Festschrift for Peter Dronke. 2001. ISBN 9004119647

30. Teeuwen, M. Harmony and the Music of the Spheres. The Ars Musica in Ninth-Century Commentaries on Martianus Capella. 2002. ISBN 9004125256

31. O'Sullivan, S. Early Medieval Glosses on Prudentius' Psychomachia. The Weitz Tradition. 2004. ISBN 9004138048

32. Könsgen, E. Iohannes de Garlandia. Carmen de Misteriis Ecclesie. Mit einem Kommentar von Peter Dinter. 2004. ISBN 9004139532

33. Marcovich, M.† M. Marvli Delmatae Davidias. 2006. ISBN 9004149635

34. Jiroušková, L. Die Visio Pauli. Wege und Wandlungen einer orientalischen Apokryphe im lateinischen Mittelalter, unter Einschluß der alttschechischen und deutschsprachigen Textzeugen. 2006. ISBN-13: 978900415055 3, ISBN-10: 9004150552

35. Colker, M.L. (Ed.). Petronius Rediuiuus et Helias Tripolanensis. id est Petronius Rediuiuus Quod Heliae Tripolanensis Videtur Necnon Fragmenta (Alia) Heliae Tripolanensis. 2007. ISBN 9789004157071

36. Kretschmer, M.T. Rewriting Roman History in the Middle Ages. The 'Historia Romana' and the Manuscript Bamberg, Hist. 3. 2007. ISBN 9789004157101

37. Cardelle de Hartmann, C. Lateinische Dialoge 1200-1400. Literaturhistorische Studie und Repertorium. 2007. ISBN 9789004160330 